\title{
Genome-wide transcriptome analysis and identification of benzothiadiazole-induced genes and pathways potentially associated with defense response in banana
}

Zhihao Cheng ${ }^{1 \dagger}$, Xiang $\mathrm{Yu}^{2+}$, Shuxia $\mathrm{Li}^{3}$ and Qiong $\mathrm{Wu}^{{ }^{1 *}}$

\begin{abstract}
Background: Bananas (Musa spp.) are the most important fruit crops worldwide due to their high nutrition value. Fusarium wilt of banana, caused by fungal pathogen Fusarium oxysporum f. sp. cubense tropical race 4 (Foc 4), is considered as the most destructive disease in the world and results in extensive damage leading to productivity loss. The widespread use of plant resistance inducers (PRIs), such as benzothiadiazole (BTH), is a novel strategy to stimulate defense responses in banana plants to protect against pathogens infection. The recent focus on the crop defense against fungal infections has led to a renewed interest on understanding the molecular mechanisms of specific PRIs-mediated resistance. This transcriptome study aimed to identify genes that are associated with BTHinduced resistance. Patterns of gene expression in the leaves and roots of BTH-sprayed banana plants were studied using RNA-Seq.

Results: In this study, 18 RNA-Seq libraries from BTH-sprayed and untreated leaves and roots of the Cavendish plants, the most widely grown banana cultivar, were used for studying the transcriptional basis of BTH-related resistance. Comparative analyses have revealed that 6689 and 3624 differentially expressed genes were identified in leaves and roots, respectively, as compared to the control. Approximately $80 \%$ of these genes were differentially expressed in a tissue-specific manner. Further analysis showed that signaling perception and transduction, transcription factors, disease resistant proteins, plant hormones and cell wall organization-related genes were stimulated by BTH treatment, especially in roots. Interestingly, the ethylene and auxin biosynthesis and response genes were found to be up-regulated in leaves and roots, respectively, suggesting a choice among BTH-responsive phytohormone regulation.
\end{abstract}

Conclusions: Our data suggests a role for BTH in enhancing banana plant defense responses to Foc 4 infection, and demonstrates that BTH selectively affect biological processes associated with plant defenses. The genes identified in the study could be further studied and exploited to develop Foc 4-resistant banana varieties.

Keywords: Banana, Fusarium wilt, Transcriptome, Resistance inducers, Plant phytohormones, Cell wall modification

\footnotetext{
* Correspondence: wuqiong2046@126.com

'Zhihao Cheng and Xiang Yu contributed equally to this work.

${ }^{1}$ Haikou Experimental Station, Chinese Academy of Tropical Agricultural

Sciences, Haikou 570102, China

Full list of author information is available at the end of the article
}

(c) The Author(s). 2018 Open Access This article is distributed under the terms of the Creative Commons Attribution 4.0 International License (http://creativecommons.org/licenses/by/4.0/), which permits unrestricted use, distribution, and reproduction in any medium, provided you give appropriate credit to the original author(s) and the source, provide a link to the Creative Commons license, and indicate if changes were made. The Creative Commons Public Domain Dedication waiver (http://creativecommons.org/publicdomain/zero/1.0/) applies to the data made available in this article, unless otherwise stated. 


\section{Background}

The inability of higher plants to escape from microbial pathogen attacking has led to the development of a diverse set of constitutive and/or inducible defence mechanisms to resist and coexist with their pathogens [1]. Ongoing researches are revealing that a typical plant immune response includes a series of consecutive reactions from pathogen recognition, signal transduction, and hormone-mediated downstream defense responses [1,2]. To recognize and cope with pathogens, plants have evolved two inducible immune systems that include pathogen-associated molecular pattern (PAMP)-triggered immunity (PTI) and effector-triggered immunity (ETI) [3]. On the external face of the host plant cell, PTI is induced when PAMPs are recognized by receptor proteins called pattern recognition receptors (PRRs). ETI is initiated by recognition of pathogen avirulence molecules called effectors by the plants disease-resistance (R) proteins [1]. Although PTI and ETI lead to similar responses, ETI is generally stronger and faster, and often gives rise to programmed cell death called the hypersensitive response (HR) and systemic acquired resistance (SAR) in the host [1].

Both PTI- and ETI-associated immune responses act through a common set of signaling components, including $\mathrm{Ca}^{2+}$, reactive oxygen species (ROS) and multiple protein kinases. These signaling components modulate downstream regulatory protein activities, such as transcription factors (TFs), which lead to massive transcriptional reprogramming and result in accumulation of various enzymes, pathogenesis-related (PR) proteins and pathogen infection-responsive metabolites [1]. The changes in cytosolic $\mathrm{Ca}^{2+}$ concentration in plant cells are believed to be one of the early intracellular reactions following pathogen perception, which are sensed by $\mathrm{Ca}^{2+}$-binding proteins and kinases, such as calcium dependent protein kinases (CDPKs) and mitogen-activated protein kinases (MAPKs) [2, 4]. In Arabidopsis, CDPKs have proved to be required for FLS2-dependent immunity [5]. Importantly, previous studies have also shown that MAPK cascade acts downstream of flagellin perception in Arabidopsis [6]. Moreover, transcription factors including ethylene response factors (ERFs) and WRKYs can be activated by MAPKs, and play broad and pivotal roles in regulating defenses $[7,8]$. Genome-wide analyses of MAPK signaling and WRKY genes that are responsive to Sclerotinia. sclerotiorum in Brassica. napus have been reported [9]. ROS serves as a major signaling molecule in plant defense response [1]. A rapid production of ROS in an oxidative burst, which is largely derived from the activity of membrane-localized NADPH oxidases, was observed after infection with a pathogen in plants [10]. According to an earlier study, the expression levels of NADPH oxidases were increased in the resistant banana cultivar in response to Foc 4 infection [11], indicating the crucial role of ROS in plant defence.

In the last decades, phytohormones such as salicylic acid (SA), jasmonic acid (JA), ethylene (ET), abscisic acid (ABA) and auxin, have been extensively studied and demonstrated to play conserved and divergent roles downstream of PTI or ETI activation in defense responses [12, 13]. According to the previous studies, SA triggers defence responses against biotrophic and hemibiotrophic invading pathogens in various species, whereas JA and ET activate responses against necrotrophic pathogens [14]. It has been found that SA accumulation and signaling is enhanced during plant-pathogen interactions in many species [14-16]. In tomato mutants with impaired in SA accumulation and perception exhibited increased susceptibility against to Fusarium pathogen infection, indicating the importanceof SA in plant defence [17]. Exogenous application of SA or synthetic SA analogs, such as benzothiadiazole $(\mathrm{BTH})$, potentiated responses to various pathogens in a wide range of tested plants including Arabidopsis, tomato, wheat and cucumber [18-21]. The non-expressor of pathogenesis related gene 1 (NPR1) is an essential component of SA-induced signaling pathway and SAR. It was observed that $N P R 1 A$ and $N P R 1 B$ were strongly induced by Foc infection in banana [22]. Consistent with the defense promoting role of SA, ET and JA have also been demonstrated to fine-tune immunity in plantpathogen interactions [14]. Mutations in Ethylene receptor 1 (ETR1) and Ethylene-insensitive 2 (EIN2), two essential components of ET perception and transduction, showed a reduction of disease symptoms compared to the wild-type upon Fusarium oxysporum f.sp. conglutinans (Focn) or Fusarium oxysporum f.sp. raphani (Forp) inoculation in Arabidopsis [23, 24]. Accordingly, loss-of-function mutations in Coronatine-Insensitive 1 (COI1) that are required for JA-mediated defense also resulted in strongly increased resistance to Focn [25]. In contrast to the hormones aforementioned, the role of auxin in modulating the defense pathways has not been systematically analyzed. Previously, auxin was believed to be involved in mediating plant growth and organogenesis [26, 27]. Recently, the altered accumulations of auxin in plant-pathogen interaction suggests that this hormone may play an important role in plant defence $[28,29]$.

Fusarium wilt, which is mainly caused by the fungal pathogen Fusarium oxysporum f. sp. cubense tropical race 4 (Foc 4), is a soil-borne lethal disease of Cavendish bananas in the world [2, 30,31]. The Foc 4 infects host banana plants through attaching to the root surface, penetrating and subsequent colonizing the xylem vessels, and causes a reddish-brown discoloration of the rhizome and pseudostem [32]. Typical disease symptoms of 
Fusarium wilt mainly include progressive wilting; yellow leaves followed by stunting and eventually plant death [30]. Susceptible banana cultivars could not be produced in previously infested plantations for a long period of time, up to 30 years, due to the pathogen's long persistence in the absence of the host [30]. Since the 1990s, Foc 4 emerged and spread rapidly in the tropics of Africa and Asia, and was considered as a major threat to Cavendish cultivars production worldwide [2]. Previous studies indicated that a diverse range of methods can be used to combat or manage this disease [30]. Among them, identification of new cultivars by resistance breeding remains the most promising option to overcome the Fusarium wilt of banana plants. However, identification of resistant cultivars is time consuming and sometimes is hindered by low seeds production of triploid banana. Importantly, application of nontoxic 'resistance inducer' is also a preferred method to control plant diseases through induction of plants' defense mechanisms [33]. A great number of exogenous molecules have been effectively used against pathogen in many species, such as $\beta$ -aminobutyric acid (BABA), hexanoic acid and BTH [33]. BTH has been reported to be effective in the management and prevention of pathogen infection through activating SAR genes that encode PR proteins, ROS scavenger enzymes and the chitinase in several species $[18,34,35]$, but it has not been shown to protect banana against Foc 4 infection until now. In this study, we found that spraying of banana plants (Cavendish cultivars) with BTH reduce disease incidence and severity caused by Foc 4 , revealing the ability of BTH to induce the banana plant immune system. However, how exactly BTH levels influence banana defense to Foc 4 remains to be addressed. RNA sequencing (RNA-Seq) analysis is a powerful approach to study transcriptomes, and has led the way to identify BTH-responsive signaling pathways tightly linked to Fusarium wilt that are highly valued in breeding. Importantly, previous studies mainly focused on studying the molecular mechanism of susceptible banana infected with Foc 4 [11, 36-39], a global analysis of the transcriptome responses associated with resistance inducer has not yet been performed. Therefore, to determine the effects of BTH on plant metabolism, we analyzed the transcriptome of Cavendish banana leaves and roots treated with BTH. Our study helped us to understand BTH-mediated host defenses against Foc 4 in banana and to formulate strategies to protect plants by using resistance inducers.

\section{Methods}

\section{Plant material and Foc 4 inoculations}

Cavendish banana (Musa spp. AAA group) was used in the study. Two-month-old seedlings were grown in plastic pots filled with sterilized soil at $26 \pm 2{ }^{\circ} \mathrm{C}$ with a $16 \mathrm{~h} /$
$8 \mathrm{~h} \mathrm{light/dark}$ period and with $80-90 \%$ relative humidity in greenhouse of Chinese Academy of Tropical Agricultural Sciences, Haikou of China (N20 $02^{\prime}$ and E110 $11^{\prime}$ ). The BTH treatment was performed by spraying the leaves of the banana plant with the $50 \mathrm{mg} / \mathrm{L}, 100 \mathrm{mg} / \mathrm{L}$ BTH. Plants sprayed with distilled water were used as the negative controls. For inoculation, the Foc 4 was used to inoculate roots as previously described [32], and at least 20 individual plants for each treatment of three replicated assays were phenotypically screened at 30 days post inoculation. Fusarium wilt disease was monitored based on the observation of typical wilt symptoms, and the disease incidence was calculated as the percentage of infected plants among the total number of plants. The differences of disease incidence between groups were determined by one-way analysis of variance (ANOVA) as previously described [40]. For RNA-sequencing, six individual banana seedlings planted in pots were sprayed with $100 \mathrm{mg} / \mathrm{L} \mathrm{BTH}$, and the youngest leaves and roots were collected at 1st day post treatment (dpt) and $3 \mathrm{dpt}$, respectively, and then were frozen in liquid nitrogen immediately. Based on the previous studies, the transcripts level of SAR markers and the number of BTHresponsive genes were increased gradually and reached the peak at $24 \mathrm{~h}$ after BTH treatment $[18,41,42]$. Meantime, we speculated that the effect of BTH on banana transciptome may also be different over the time, and we proposed two types of response, including short-term transient response (1 day) and long-term response (3 days). Thus, we choose these two sampling time points. For each sampling time and treatment, three replicated samples were collected from both the treated and control plants.

\section{RNA-Seq and data analysis}

For RNA-Seq, the total RNA isolation, cDNA libraries preparation and RNA deep sequencing were performed by the Annoroad Gene Technology Corporation (Beijing, PR China). A total of 105 gigabase raw sequence reads of 18 libraries was obtained initially on a HiSeq 2500 instrument that generated paired-end reads with 150 nucleotides in length. We discarded reads with adapters, those with more than 5\% unknown nucleotides, and those of low quality ( $\geq 15 \%$ of the bases with a quality score $(\mathrm{Q}) \leq 19)$. The average proportion of clean reads in each sample was $88.5-90.2 \%$. The filtered clean reads from each sample were aligned to the reference banana genome with mapping rate $73-78 \%$, and were assembled into non-redundant unigenes using Cufflinks v2 method [43]. The FPKM (fragments per kilo base of transcript per million mapped reads) was employed to estimate the abundance of unigenes [44]. The differential expression analysis between treatments and controls was performed using cuffdiff program, and the significant DEGs for 
further data analysis were filtered with false discovery rate (FDR) corrected $P$ value $\leq 0.05$ and fold change $\geq 2$. The RNA-Seq data was submitted to BioProject in NCBI under the accession number PRJNA417328.

\section{Functional annotation of DEGs and pathways}

To obtain functional annotation and identify the putative biological pathways of DEGs, we annotated the DEGs using the NR protein database (NCBI), GO and KEGG databases with similarity set at $>30 \%$ and an E-value $\leq 1 \mathrm{e}^{-5}$. As described previously [45], The GO seq $\mathrm{R}$ package was employed to attain GO-based classification and pathway mapping [46]. KOBAS software was used to calculate the statistical enrichment of DEGs in KEGG pathway [47]. The FDR was used to determine the threshold of the $P$-value in GO and KEGG analyses. We used an FDR of $<0.05$ as thresholds to define significantly enriched GO terms and KEGG pathways.

\section{Real-time quantitative PCR verification}

Total RNA was isolated from the leaf and roots of banana plants sprayed with $100 \mathrm{mg} / \mathrm{L} \mathrm{BTH}$, as described above. First-strand cDNA synthesis was performed using PrimeScript $^{\text {tm }}$ RT reagent Kit (Takara) according to the manufacturer's instructions, using $2 \mu \mathrm{g}$ total RNA and oligo(dT) primers. qRT-PCR was performed using SYBR ${ }^{\circ}$ qPCR Mix (Toyobo, Tokyo, Japan) according to the manufacturer's protocol. The cycling conditions were as follows: 5 min denaturation at $95{ }^{\circ} \mathrm{C}$, followed by 40 cycles at $95{ }^{\circ} \mathrm{C}$ for $15 \mathrm{~s}$, and $60{ }^{\circ} \mathrm{C}$ for $40 \mathrm{~s}$. Melting curve analysis was performed over the range of 65 to $98{ }^{\circ} \mathrm{C}$. The primers used in this study were listed in Additional file 1: Table S7. All qRT-PCR reaction was repeated three times and the relative mRNA expression level was calculated as $2^{-\Delta \Delta C t}$. The banana MaACTIN gene was used as a constitutive reference. The qPCR data were presented as means \pm SD. Asterisks indicate significant differences compared with the control by Student's t-test.

\section{Results}

Chemically induced resistance in banana against Foc 4

BTH has already been documented to be an identical efficient activator of disease resistance in several plant species [18, 34, 35]. However, little is known about whether BTH is effective against Fusarium wilt caused by Foc 4 in Cavendish bananas. To evaluate its activity on banana, leaves of two-month-old plants (with four true leaves) were sprayed with water or BTH, 1 day prior to inoculation of the roots with Foc 4. Based on previously reported $\mathrm{BTH}$ concentrations for foliar treatments in different plants, $50 \mathrm{mg} / \mathrm{L}$ and $100 \mathrm{mg} / \mathrm{L} \mathrm{BTH}$ treatments were employed. These concentrations had no visible effect on banana plant development. Thirty days after inoculation, the disease severity was analyzed statistically. As shown in Fig. 1, more than $76.6 \%$ of control plants inoculated with Foc 4 exhibited very severe symptoms, while almost $70.1 \%$ of Foc 4-infected plants pre-treated with BTH were symptomless. Symptoms in control plants consisted of leaf yellowing, and as the disease progresses, a pronounced stunting of the whole plants was observed. The results indicated that BTH is able to enhance banana resistance to Foc 4 without affecting the growth of banana seedlings.

\section{Overview of banana transcriptome after BTH treatment}

To achieve a broad survey of new candidates important in BTH-mediated plant defense response, RNA-Seq data were generated from banana leaves and roots sampled 1 and 3 days from plants leaves sprayed with BTH, as compared to the control. At least three replicates for each treatment were harvested. Using an Illumina paired-end sequencing platform, over one billion reads from BTH-treated and control libraries were produced. After removing low quality reads, 43 million to 47 million reads per sample were mapped against the reference $\mathrm{Musa}$ spp. genome and assembled into 38,995 transcripts (Table 1). By comparing these transcripts with the annotated genes in the banana genome, an average of $89.7 \%$ of total transcripts matched the predicted banana protein-coding sequences and 34,999 non-redundant unigenes were obtained. Notably, after filtering out low-abundance $($ FPKM $<1)$ and noncoding genes, a total of 3996 protein-coding transcripts that showed no overlap with any annotated genes, were characterized as reference-dependent novel potential protein-coding genes (Table 1, Additional file 2: Table S1).

\section{Differentially expressed genes responsive to BTH spraying in banana plants}

To evaluate the expression value of 34,999 annotated banana protein-coding genes for each sample, the number of clean reads that mapped to each gene was calculated, and then normalized into FPKM (fragments per $\mathrm{kb}$ exon model per million mapped fragments). By analyzing the expression patterns of these genes in leaves and roots for each time point, we observed a large number of genes that exhibited highly dynamic changes after 1 day BTH treatment in both leaves and roots (Fig. 2a). Furthermore, the expression changes of each gene in BTH treated leaves and roots in comparison to untreated control were investigated. We used a stringent value of FDR $<0.05$ as the threshold to judge the significant differences in the gene expressions. Across all of the times tested, a total of 8621 differentially expressed genes (DEGs) were identified after BTH treatment in banana (Additional file 3: Table S2). More specifically, 6689 and 3624 DEGs were significantly modulated by 


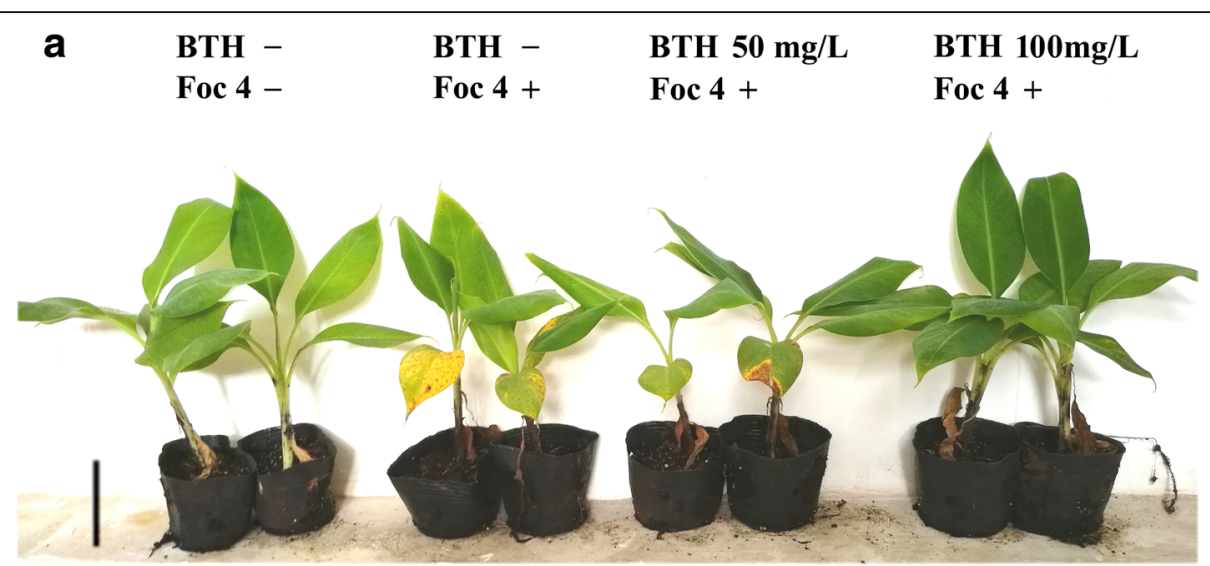

b

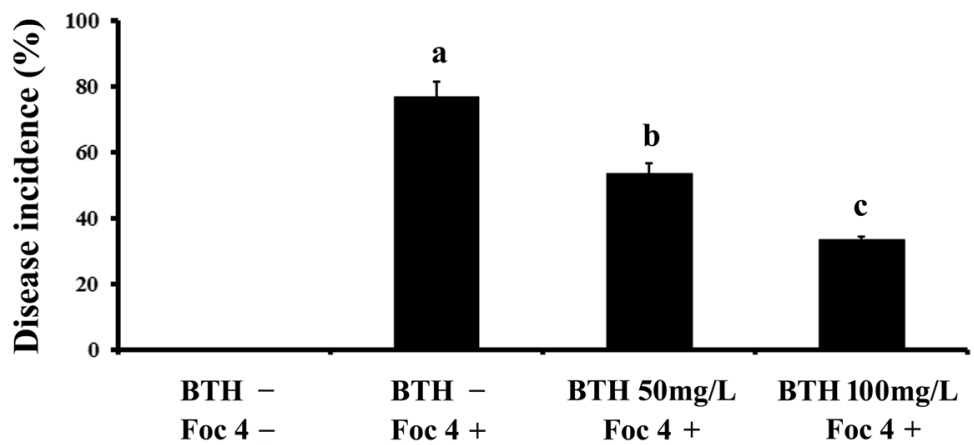

Fig. 1 Growth of banana plants following treatment with BTH and Foc 4 inoculation. a Two-month-old banana plants (with four true fully expanded leaves) were pre-treated with $\mathrm{H}_{2} \mathrm{O}, 50 \mathrm{mg} / \mathrm{L}$ BTH or $100 \mathrm{mg} / \mathrm{L} \mathrm{BTH}$. The roots were infected with Foc 4 or untreated one day later. Plants were photographed 4 weeks post inoculation; b) Fusarium wilt disease incidence rate (calculated by the formula: number of infected plants/ total number of inoculated plants) of Foc 4 inoculated or untreated plants. Data are presented as mean \pm SD of three independent assays, and the different letters indicate significant differences $(P<0.05)$ according to ANOVA test. The total number of plants observed was $>20$ in each group from three biological replicates

BTH in leaves and roots, respectively. The numbers of DEGs for each time point were shown in Fig. $2 b$ and Additional file 3: Table S2. Among the up-regulated genes, at all time points, 46.1 and $44.4 \%$ of the genes were specifically modulated by BTH in leaves and roots, respectively (Fig. 2c). Among the down-regulated genes, 87.9 and $10.3 \%$ of the genes were uniquely altered by BTH in leaves and roots, respectively (Fig. 2d). These results indicated that most of the DEGs were responsive to BTH spraying in a tissue-specific manner.

\section{Functional sanalysis of BTH-responsive DEGs}

To functionally classify those BTH-responsive DEGs, gene ontology (GO) enrichment analysis of all the DEGs was utilized, and a total of 298 GO terms were significantly enriched (Additional file 4: Table S3). In Table 2, we listed the top 5 specific and common GO terms enriched in leaves and roots, respectively. After 1 day BTH treatments, DEGs involved in organonitrogen compound metabolic, pigment metabolic and chlorophyll metabolic processes were significantly enriched in leaves.

Table 1 Summary of the read numbers aligned onto the banana reference genome

\begin{tabular}{lllllll}
\hline Samples & Total Reads & Mapped Reads & Mapping Rate & Multi Map Reads & Annotated transcripts & Novel transcripts \\
\hline LF Od & $61,783,609$ & $47,826,265$ & 0.77 & 339,914 & 32,340 & 2802 \\
LF 1d & $62,428,631$ & $46,940,149$ & 0.75 & 533,631 & 32,009 & 2754 \\
LF 3d & $60,616,740$ & $47,198,078$ & 0.78 & 424,275 & 32,081 & 2163 \\
RT Od & $60,117,134$ & $43,751,447$ & 0.73 & 908,342 & 33,176 & 3370 \\
RT 1d & $60,981,186$ & $46,515,067$ & 0.76 & 509,560 & 33,750 & 3219 \\
RT 3d & $61,128,012$ & $44,891,051$ & 0.73 & 634,339 & 33,437 & 3161 \\
In total & $1,101,165,940$ & $831,366,175$ & 0.75 & $10,050,186$ & 34,999 & 3996 \\
\hline
\end{tabular}




\section{a}

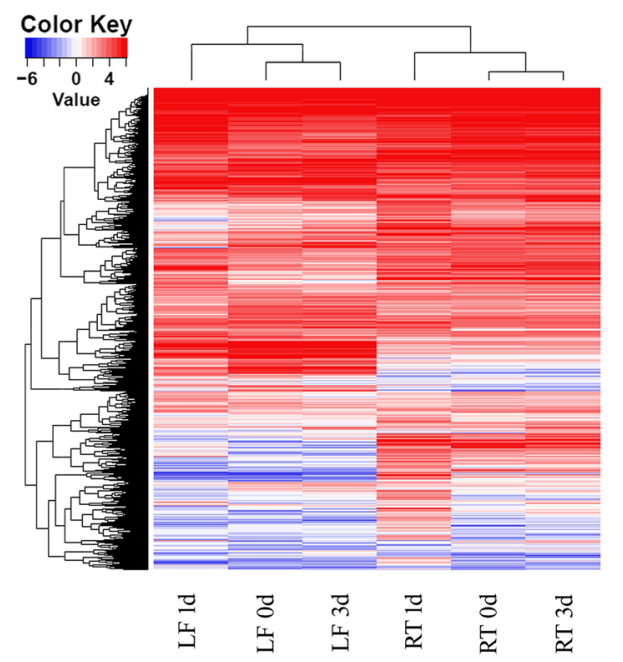

b

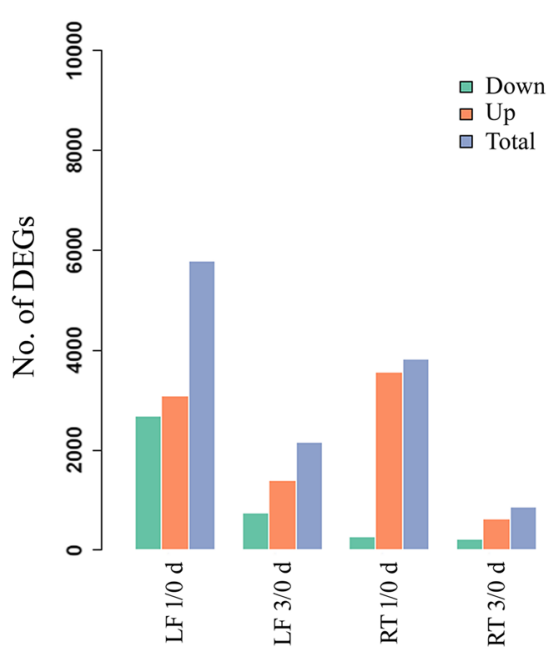

d

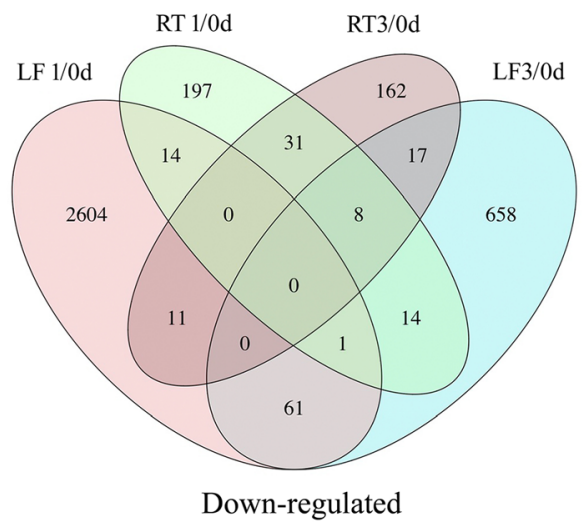

Fig. 2 Variation in gene expression of BTH-sprayed banana plants. a The abundance of all of the expressed genes in leaves and roots; b) Comparison of the number of up- and down-regulated DEGs between treatments and control; $\mathbf{c}, \mathbf{d}$ ) Venn diagram represents the overlapping up- and down-regulated DEGs number between leaves and roots, respectively. LF, leaf; RT, root

While the cell wall organization or biogenesis and external encapsulating structure organization processes were identified in DEGs of roots. Additional analysis revealed that DEGs associated with single-organism biosynthetic or metabolic and small molecule biosynthetic processes were commonly overexpressed in both leaves and roots. At the third day after BTH spraying, there was differential modulation on the processes including DNA-templated transcription, RNA biosynthetic and heterocycle biosynthetic in leaves. In contrast, DEGs involved in cellular response to oxygen-containing compound, response to oxygen-containing compound and jasmonic acid mediated signaling pathway were obviously affected in roots. Notably, a large number of DEGs related to biotic and abiotic stimulus responding were significantly enriched in both leaves and roots.
To further understand the functions of DEGs, we mapped all of DEGs in the kyoto encyclopedia of genes and genomes (KEGG) database to discover those genes involved in metabolic or signal transduction pathways. We identified 15 and 25 pathways that were significantly enriched in leaves and roots, respectively, which were in agreement with the GO terms results (Additional file 5: Table S4). Table 3 presents the overall response pathways of banana leaves and roots to BTH treatments at two time points, respectively. We observed that most of the pathways (12/15 in leaves and 20/25 in roots) were involved in various metabolic pathways across all of the times tested, including amino acid, nucleotide-sugar, steroid, sucrose, linoleic acid and biosynthesis of other secondary metabolites. More importantly, one common feature was also observed in both leaves and roots: 
Table 2 GO terms of biological process classification of DEGs in leaves and roots

\begin{tabular}{|c|c|c|c|c|c|c|c|}
\hline LF-specific 1/0d & $\mathrm{GO} I \mathrm{D}$ & Up & Down & RT-specific $1 / 0 d$ & GO ID & Up & Down \\
\hline Organonitrogen compound metabolic & GO:1901564 & 148 & 261 & Cell wall organization or biogenesis & GO:0071554 & 229 & 3 \\
\hline Pigment metabolic process & GO:0042440 & 27 & 65 & Cell division & GO:0051301 & 184 & 5 \\
\hline Chlorophyll metabolic process & GO:0015994 & 15 & 35 & External encapsulating structure organization & GO:0045229 & 198 & 3 \\
\hline Small molecule metabolic process & GO:0044281 & 214 & 361 & Carbohydrate metabolic process & GO:0005975 & 365 & 8 \\
\hline Photosynthesis & GO:0015979 & 10 & 84 & Cell cycle & GO:0007049 & 208 & 5 \\
\hline \multicolumn{8}{|l|}{ Common $1 / 0 d$} \\
\hline Single-organism metabolic process & GO:0044710 & 456 & 664 & & & 745 & 39 \\
\hline Small molecule biosynthetic process & GO:0044283 & 82 & 149 & & & 158 & 8 \\
\hline Carbohydrate biosynthetic process & GO:0016051 & 49 & 80 & & & 102 & 1 \\
\hline Organic hydroxy compound biosynthetic & GO:1901617 & 23 & 45 & & & 54 & 3 \\
\hline Lipid metabolic process & GO:0006629 & 128 & 177 & & & 202 & 12 \\
\hline LF-specific 3/0d & GO ID & Up & Down & RT-specific 3/0d & GO ID & Up & Down \\
\hline DNA-templated transcription & GO:0006351 & 221 & 128 & Jasmonic acid mediated signaling pathway & GO:0009867 & 19 & 4 \\
\hline RNA biosynthetic process & GO:0032774 & 221 & 128 & $\begin{array}{l}\text { Cellular response to oxygen-containing } \\
\text { compound }\end{array}$ & GO:1901701 & 47 & 14 \\
\hline Heterocycle biosynthetic process & GO:0018130 & 242 & 139 & Defense response to bacterium & GO:0042742 & 29 & 5 \\
\hline Aromatic compound biosynthetic process & GO:0019438 & 261 & 142 & Cellular response to jasmonic acid stimulus & GO:0071395 & 19 & 4 \\
\hline Organic cyclic compound biosynthetic & GO:1901362 & 267 & 145 & Cellular response to acid chemical & GO:0071229 & 33 & 12 \\
\hline \multicolumn{8}{|l|}{ Common 3/0d } \\
\hline Response to organonitrogen compound & GO:0010243 & 54 & 9 & & & 34 & 3 \\
\hline Response to endogenous stimulus & GO:0009719 & 194 & 69 & & & 121 & 29 \\
\hline $\begin{array}{l}\text { Response to oxygen-containing } \\
\text { compound }\end{array}$ & GO:1901700 & 162 & 50 & & & 106 & 26 \\
\hline Defense response & GO:0006952 & 141 & 31 & & & 69 & 22 \\
\hline Response to organic substance & GO:0010033 & 200 & 78 & & & 126 & 30 \\
\hline
\end{tabular}

plant-pathogen interaction pathway was notably enriched at the 3rd day post treatment (dpt). A few differences between the two tested tissues were also observed: cell cycle and plant hormone signal transduction pathways were specifically enriched in roots. Taken together, these results pointed, for the first time, a role of BTH in promoting pathogen resistance, especially in roots, by modulating differential gene transcription globally.

\section{BTH-responsive DEGs related to signal perception and transduction}

Ongoing research is revealing that the protein kinases act as master regulators in plant adaptions to biotic stresses $[48,49]$. In total, 545 protein kinases were identified to be responsive to BTH treatment, including 77 overlapping DEGs in all tissues, 287 leaves-specific and 181 roots-specific DEGs. The majority of these proteins were up-regulated in both the leaves and roots (Additional file 6: Table S5). Based on the roles of these kinases in signal perception and transduction pathways, we classified these genes into several groups, including receptor-like kinases (RLKs), serine/threonine-protein kinases, MAPKs and $\mathrm{Ca}^{2+}$ sensors. The RLK group has been shown to be involved in defense/resistance against pathogens in model plants [49]. A total of 30 common signaling-related receptor kinases and RLKs that responded to $\mathrm{BTH}$ in both leaves and roots at the early response phase were identified. These genes mainly included 3 wall-associated receptor kinase-like proteins, 2 serine/ threonine-RLKs, 4 proline-rich RLKs, 3 cysteine-rich RLKs, 5 lectin domain RLKs, 2 lysM domain RLKs and 11 leucine-rich repeat (LRR)-RLKs (Fig. 3, Additional file 6: Table S5). Moreover, we also identified 7 MAPKs, 6 CBL-interacting protein kinases and 1 calcium-dependent protein kinases (CDPKs), which were accumulated to a higher level by BTH in all tissues. These results indicated that early signal perception and transduction may be enhanced in BTH-treated banana plants.

\section{Identification of BTH-regulated transcription factors}

Transcription factors (TFs) play major roles in plant development and defense response through the temporary and spatial inducing or repressing the transcription of their target genes [50]. In this study, a total of 946 
Table 3 The significantly enriched pathways of DEGs in banana leaves and roots

\begin{tabular}{|c|c|c|c|c|c|c|c|}
\hline LF-specific 1/0d & Map ID & Up & Down & RT-specific $1 / 0 d$ & Map ID & Up & Down \\
\hline Selenocompound metabolism & map00450 & 2 & 11 & Amino and nucleotide sugar metabolism & map00520 & 56 & 0 \\
\hline Carbon fixation in photosynthetic organisms & map00710 & 5 & 25 & Phenylpropanoid biosynthesis & map00940 & 42 & 2 \\
\hline Cysteine and methionine metabolism & map00270 & 10 & 17 & Steroid biosynthesis & map00100 & 18 & 0 \\
\hline Purine metabolism & map00230 & 8 & 46 & Phenylalanine metabolism & map00360 & 34 & 1 \\
\hline Porphyrin and chlorophyll metabolism & map00860 & 3 & 14 & Cell cycle & map04110 & 34 & 0 \\
\hline Sulfur metabolism & map00920 & 4 & 9 & Drug metabolism - cytochrome P450 & map00982 & 12 & 1 \\
\hline \multicolumn{8}{|l|}{ Common 1/0d } \\
\hline Biosynthesis of secondary metabolites & map01110 & 87 & 146 & & & 189 & 7 \\
\hline Glycine, serine and threonine metabolism & map00260 & 5 & 24 & & & 18 & 0 \\
\hline Metabolic pathways & map01100 & 150 & 279 & & & 295 & 12 \\
\hline Microbial metabolism in diverse environments & map01120 & 26 & 76 & & & 60 & 1 \\
\hline Starch and sucrose metabolism & map00500 & 31 & 27 & & & 48 & 1 \\
\hline LF-specific 3/0d & Map ID & Up & Down & RT-specific 3/0d & Map ID & Up & Down \\
\hline Starch and sucrose metabolism & map00500 & 13 & 11 & Plant hormone signal transduction & map04075 & 20 & 3 \\
\hline \multirow[t]{3}{*}{ Amino and nucleotide sugar metabolism } & map00520 & 15 & 6 & Phenylpropanoid biosynthesis & map00940 & 7 & 6 \\
\hline & & & & Biosynthesis of secondary metabolites & map01110 & 26 & 15 \\
\hline & & & & Phenylalanine metabolism & map00360 & 6 & 3 \\
\hline \multicolumn{8}{|l|}{ Common 1/0d } \\
\hline Plant-pathogen interaction & map04626 & 30 & 3 & & map04626 & 18 & 1 \\
\hline
\end{tabular}

TFs were identified to be responsive to $\mathrm{BTH}$ in leaves and roots, which were mainly assigned to 54 different families (Additional file 6: Table S5). Among these TFs, around $50.7 \%$ (480) of the up-regulated and $23.4 \%$ (221) of the down-regulated TFs were identified in leaves and the top four significantly changed TF families were APETALA 2/Ethylene-Responsive Factor (AP2/ERF), followed by MYB, WRKY and zinc finger (ZF) family (Fig. 4a, b). In addition, a number of development-related TFs belonging to HD-ZIP, TCP and squamosa promoter binding-like protein (SPL) families were down-regulated in leaves, indicating the developmental processes of shoots may have been inhibited temporarily by BTH. However, TFs that differentially expressed in roots exhibited a diverse trend. In addition, we found approximately $36.2 \%$ of TFs were BTH-induced, while only $7.0 \%$ (66) of them were suppressed by BTH. Particularly, the DEGs belonging to the auxin response factor (ARF) and basic helix-loop-helix (bHLH) gene families were specifically accumulated in roots, which indicated that these TFs respond to $\mathrm{BTH}$ more actively in roots rather than in shoots (Fig. 4c, d). Meanwhile, the number of up-regulated TFs was much larger than the number of down-regulated ones in roots, suggesting that transcriptional activation may be dominant over repression. Previous studies have shown that large families of TFs, such as AP2/ERF, WRKY, ZF and bHLH were response to developmental and environmental stimuli, and function downstream of the hormones, biotic, and abiotic stress signaling pathways [51-53]. For example, in grape (Vitis vinifera), 57\% (16 genes) of WRKY genes showed altered expression after biotic stress induced by a common fungal pathogen (Coniothyrium diplodiella) infection [54]. In pepper, CaWRKY27 protein positively regulates the stress resistance response to Ralstonia solanacearum infection through modulation of SA-, JA- and ET-mediated signaling pathways in tobacco [55]. The ERF proteins involved in defence responses against pathogen infection have also been extensively documented, and overexpression of ERF genes in transgenic Arabidopsis or tobacco plants induces expression of several PR and hormone-responsive genes, resulting in enhanced resistance to pathogen [56, 57]. Therefore, in this study, the different expression patterns of these TFs in leaves and roots suggested a distinct requirement for diverse developmental responses in the two tissues of BTH-sprayed plants.

\section{Tissue-dependent cell cycle genes in the BTH response} KEGG analysis revealed the induction of 34 DEGs encoding for cell cycle-related proteins and enzymes in roots at the early time point, while no significant enrichment was observed in leaves confirming the tissue-dependent involvement of cell cycle pathway in the BTH response. In Fig. 5 and Additional file 7: Table S6, the selected DEGs associated with cell cycle are reported, which mainly included 2 mitotic spindle 


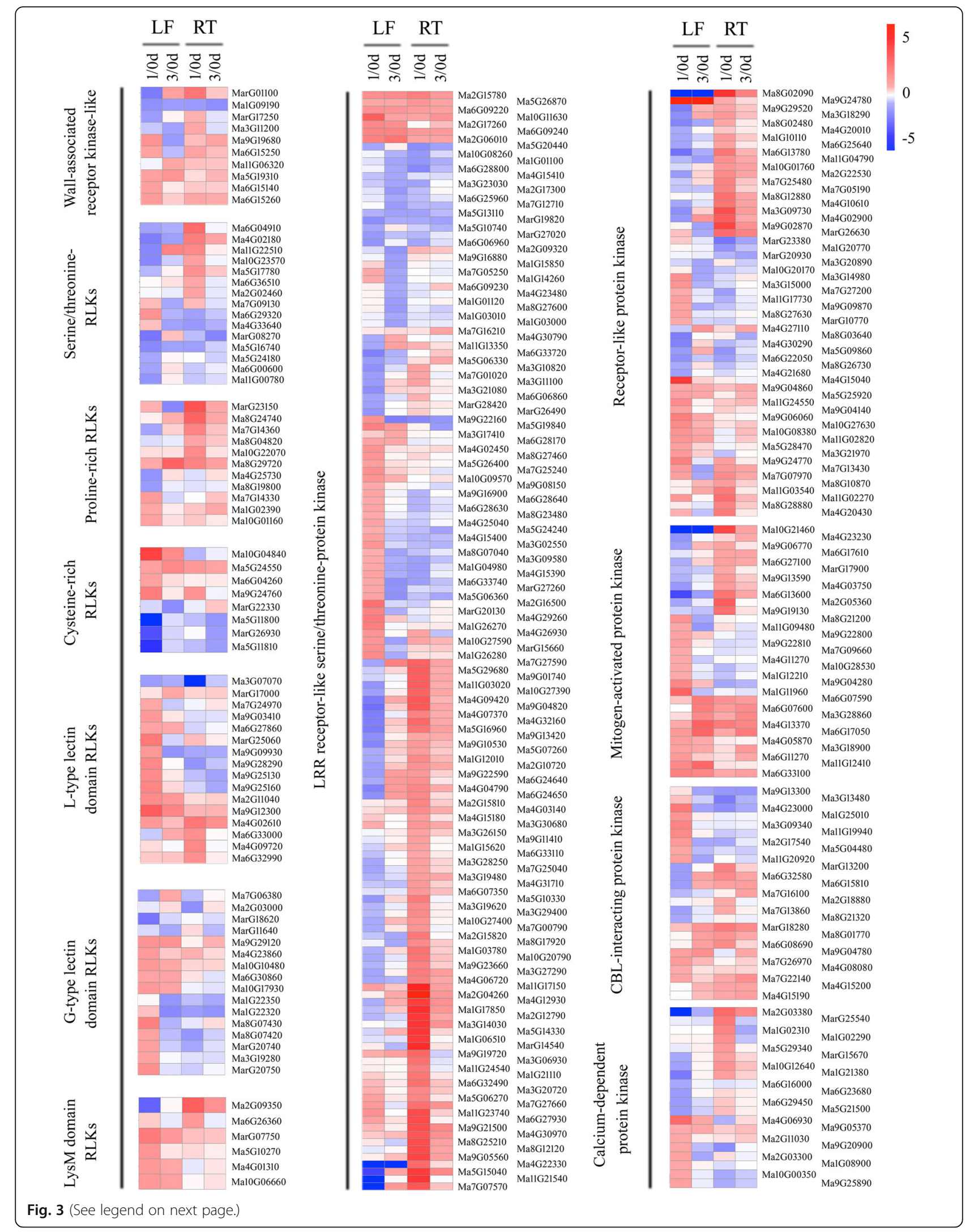


(See figure on previous page.)

Fig. 3 Expression pattern of banana protein kinases in response to BTH treatment. Heatmaps were generated from the fold change values of wall-associated receptor kinase-like, serine/threonine RLKs, proline-rich RLKs, cysteine-rich RLKs, L/G-type lectin domain RLKs, lysM domain RLKs, LRR-RLKs, receptor-like protein kinase, mitogen-activated protein kinase, CBL-interacting protein kinase and calcium-dependent protein kinase family numbers in leaves and roots from BTH-sprayed plants as compared to the control condition. LF, leaf; RT, root

checkpoint proteins (MADs), 3 mitotic spindle checkpoint proteins (Bubs), 4 Origin recognition complex subunits (Orc), 9 DNA replication licensing factors (MCMs), 3 cohesions, 2 separins, 5 cell division cycle 20 (Cdc20), 1 proliferating cell nuclear antigen (PCNA) and 34 cyclins. Precise cell-cycle control is critical for plant responses to pathogen invasion [58]. Previous study has demonstrated that the tomato B-type cyclin gene, $S l C y c B 2$, play a critical role in reproductive organ development, trichome initiation and Prodenia litura defense [59]. The increases in the abundances of DNA replicationand cell cycle-related DEGs might result in accelerating the root cell division rate under treatment, which may be an important defense reaction in BTH-treated banana against Foc 4.

\section{BTH induces synthesis and response of plant phytohormones}

To determine whether BTH influenced the hormone signaling pathways, we analyzed the expression changes of auxin, ABA, JA, SA and ET biosynthesis- and response-related genes in the leaves and roots of banana. In roots, $\mathrm{BTH}$ treatment significantly altered the expression of 21 genes involved in auxin signaling pathways, including auxin biosynthesis, polar transport and auxin-responsive genes (Fig. 6, Additional file 7: Table S6). For example, YUCCA protein, which encodes an indole3-pyruvate monooxygenase, was identified as the crucial component of the auxin biosynthetic process. We identified three YUCCAs, such as Ma8G00130, Ma3G08830 and Ma11G12150, were up-regulated by BTH in roots. Similarly, Two PIN proteins (Ma7G17140 and Ma8G29780), which mainly function as auxin efflux carriers, were also triggered by BTH in roots. However, the majority of these auxin-related DEGs (80.9\%) were found to be down-regulated or unchanged during the two stages in leaves. Oppositely, genes involved in ET biosynthetic and signaling transduction processes were predominantly increased in leaves, and only a few of these genes were affected at both time points in roots (Fig. 6, Additional file 7: Table S6). For instance, Four ET biosynthesis genes, ACC synthase (ACS, MarG20420, MarG26960, Ma3G02870 and Ma4G29150) were increased significantly after BTH treatment. Moreover, one ethylene receptor (ETR, Ma8G14350) and two EIN3-binding F-box proteins (EBF, Ma9G28510 and
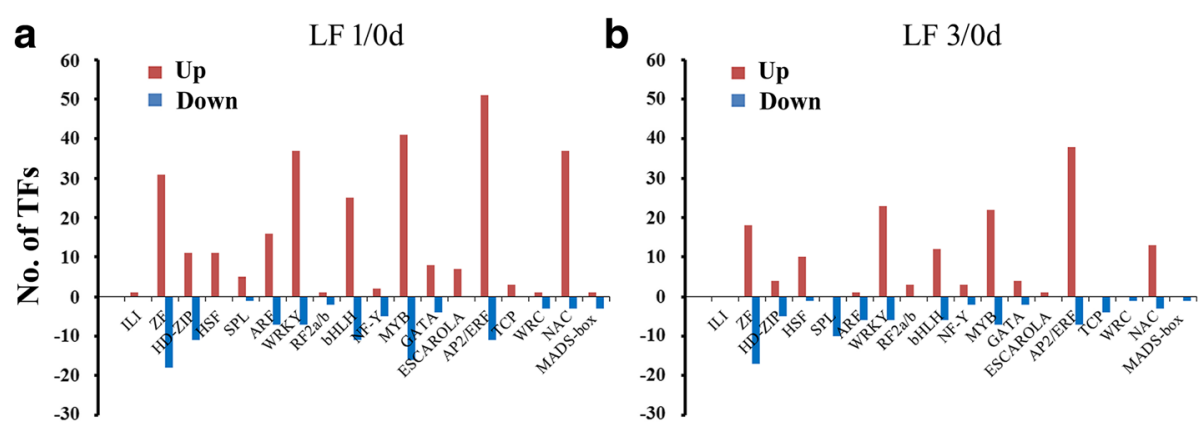

C

\section{d}
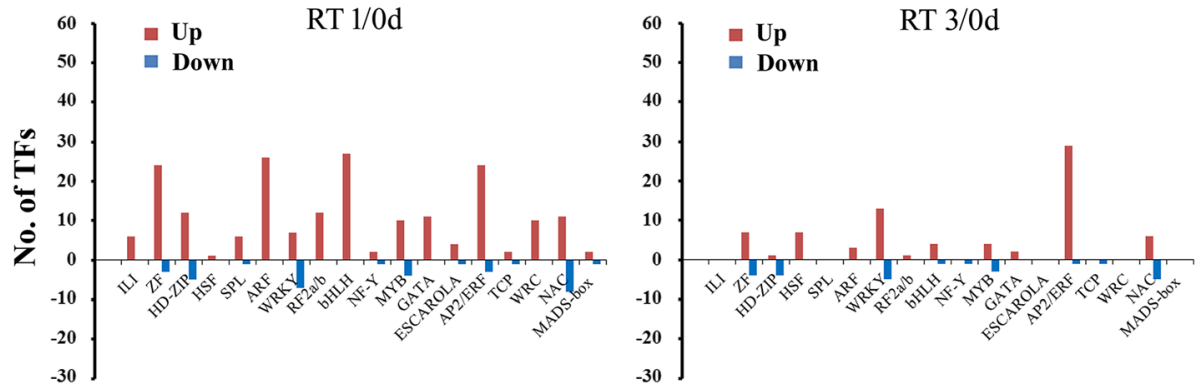

Fig. 4 Differentially expressed DEGs representing diverse families of transcription factors in leaves and roots. a-d) Comparison of the number of up- and down-regulated TFs in leaves $(\mathbf{a}, \mathbf{b})$ and roots $(\mathbf{c}, \mathbf{d})$ at the two time points, respectively. LF, leaf; RT, root 


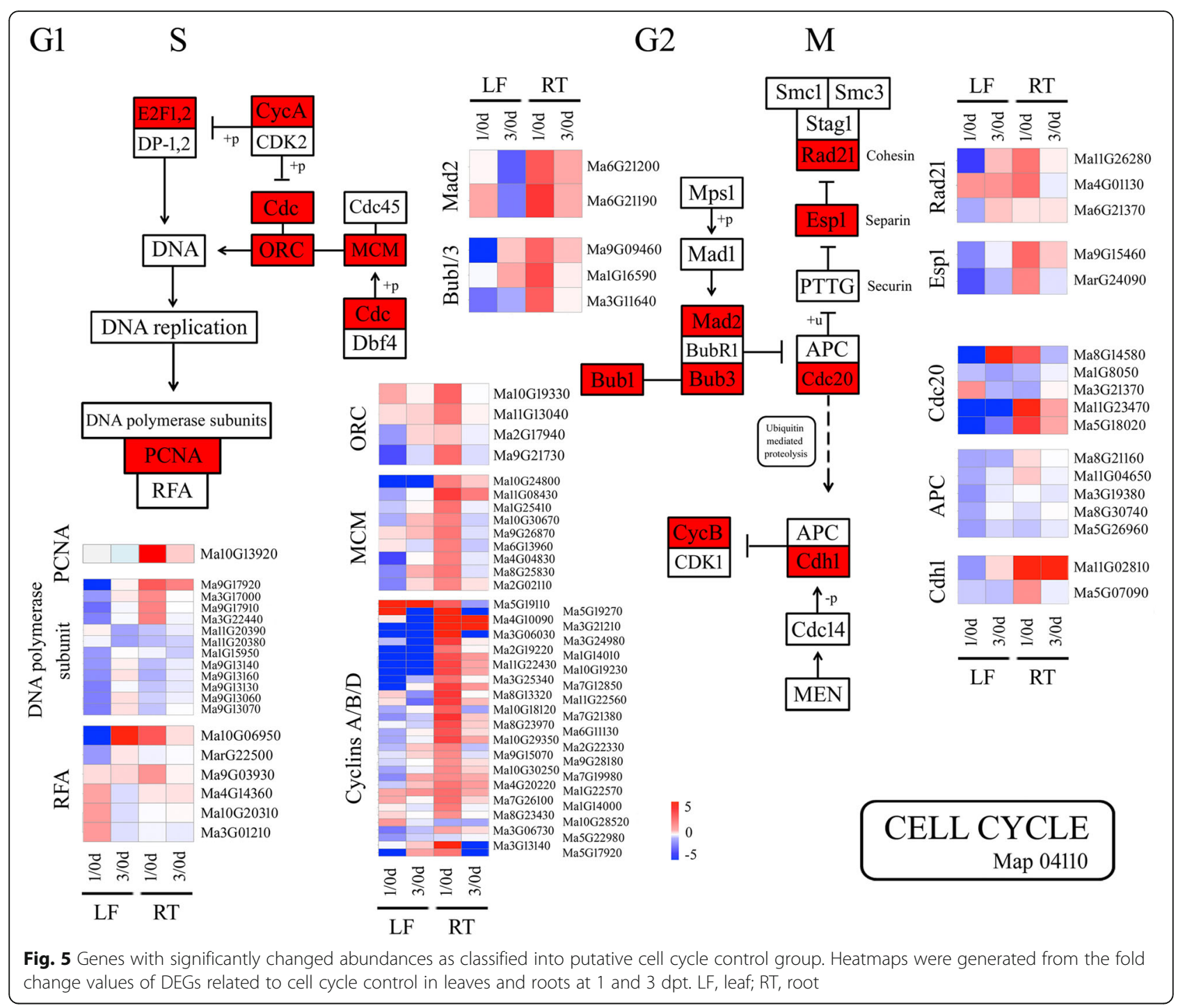

Ma4G30680), which play a significant role in perceiving and transducing the ET signals, were also induced specifically in leaves but not in roots in response to BTH-spraying (Additional file 7: Table S6). Contrary to activation of auxin and ET signaling pathways, JA and SA biosynthetic- and signaling-related genes showed no significant differences between BTH-treated and untreated plants in our results.

\section{Identification of SAR-related genes modulated by BTH}

In recent years, SAR, an inducible defense mechanism in plants against pathogens, has been demonstrated to be associated with the activation of SA signaling [60]. Several crucial components putatively involved in SAR signaling have been identified, including lipid-transfer protein DIR1 (DEFECTIVE IN INDUCED RESISTANCE 1) and PR proteins (Fig. 6). In the present study, although the SA-related signaling pathway was unaffected,
29 PRs and 4 DIR1 genes were modulated by the BTH, respectively (Fig. 6, Additional file 7: Table S6). In particular, up-regulated genes were prevalent at $1 \mathrm{dpt}$ in both the tested tissues from the banana plants, indicating that the SAR signaling may be strongly induced at this time point.

\section{Plant disease resistance protein induced by BTH}

Plant disease resistance $(\mathrm{R})$ proteins have been widely documented to play specific roles in plant-pathogen interaction through recognizing the effector molecules [2]. In the study, BTH induced up-regulation of several disease resistance proteins, which were related to pleiotropic drug resistance protein, disease resistance RPP, RPM and RGA (Fig. 6, Additional file 7: Table S6). Meanwhile, a wide variability of gene expression was also observed in BTH-sprayed leaves, and only a few of these genes were affected at the two time points in roots. 


\begin{tabular}{|c|c|c|c|c|c|c|c|c|c|c|c|c|c|c|c|}
\hline & \multicolumn{4}{|c|}{ LF } & \multicolumn{3}{|c|}{ RT } & & \multicolumn{3}{|c|}{ LF } & \multicolumn{4}{|c|}{ RT } \\
\hline & \multicolumn{2}{|c|}{ Up } & \multicolumn{2}{|c|}{ Down } & Up & \multicolumn{2}{|c|}{ Down } & & \multicolumn{2}{|c|}{ Up } & Down & \multicolumn{2}{|c|}{ Up } & \multicolumn{2}{|c|}{ Down } \\
\hline & \begin{tabular}{|l|l|}
$1 d$ & \\
\end{tabular} & $3 d$ & 1d 3 & $3 d$ & \begin{tabular}{l|l|}
$1 d$ & $3 d$ \\
\end{tabular} & 1d & $3 d$ & & \begin{tabular}{|l|l|}
$1 \mathrm{~d}$ & 3 \\
\end{tabular} & \begin{tabular}{l|l}
$3 d$ & 1 \\
\end{tabular} & \begin{tabular}{l|l|}
$1 d$ & $3 d$ \\
\end{tabular} & \begin{tabular}{l|l|}
$d$ & $1 d$ \\
\end{tabular} & \begin{tabular}{|l|l|}
$d$ & $3 d$ \\
\end{tabular} & 1d & $3 \mathrm{~d}$ \\
\hline \multicolumn{8}{|l|}{ Hormones: auxin and ethylene } & \multicolumn{8}{|l|}{ ROS metabolism } \\
\hline \multirow{7}{*}{$\begin{array}{l}\text { Auxin biosynthetic process } \\
\text { Auxin polar transport } \\
\text { Response to auxin } \\
\text { ARFs } \\
\text { Ethylene biosynthetic process } \\
\text { Ethylene-activated signaling pathway } \\
\text { ERFs }\end{array}$} & 1 & 2 & & 1 & \begin{tabular}{l|l|}
4 & 1 \\
\end{tabular} & & 1 & \multirow{10}{*}{$\begin{array}{l}\text { Polyphenol oxidase } \\
\text { Peroxidase } \\
\text { Flavin-containing monooxygenase } \\
\text { Sphinganine C(4)-monooxygenase } \\
\text { L-ascorbate peroxidase } \\
\text { L-ascorbate oxidase } \\
\text { Thioredoxins } \\
\text { Glutaredoxin } \\
\text { Glutathione S-transferase } \\
\text { Cytochrome P450 } \\
\end{array}$} & 2 & 2 & 1 & \begin{tabular}{l|l}
1 & 5 \\
\end{tabular} & 1 & 1 & \\
\hline & & & & & \begin{tabular}{l|l}
11 & 2 \\
\end{tabular} & & 2 & & \begin{tabular}{l|l}
15 & 1 \\
\end{tabular} & 10 & 1 & \begin{tabular}{l|l}
4 & 36 \\
\end{tabular} & 10 & 2 & 1 \\
\hline & 1 & & & & \begin{tabular}{l|l}
4 & \\
\end{tabular} & & & & 1 & & & 1 & 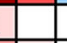 & & \\
\hline & 16 & 1 & 7 & 6 & 3 & & & & & 1 & 1 & 2 & 1 & & \\
\hline & 1 & 3 & & & 1 & & & & & 2 & 5 & 3 & 3 & & \\
\hline & 13 & 4 & 2 & 2 & \begin{tabular}{l|l}
5 & 2 \\
\end{tabular} & 1 & & & 1 & & 1 & 10 & 3 & & \\
\hline & & 38 & 11 & 7 & $2 4 \longdiv { 2 9 }$ & 3 & 1 & & 3 & 1 & 8 & 6 & \begin{tabular}{|l|l|}
2 \\
\end{tabular} & 1 & \\
\hline \multicolumn{8}{|c|}{ Systemic acquired resistance (SAR) } & & 3 & 2 & 3 & 2 & 2 & & 2 \\
\hline \multirow{3}{*}{$\begin{array}{l}\text { Pathogenesis-related (PR) protein-1 } \\
\text { Thaumatin-like protein PR-5 } \\
\text { Lipid-transfer protein DIR1 }\end{array}$} & 2 & & & 3 & \begin{tabular}{l|l}
2 & 1 \\
\end{tabular} & 6 & \multirow{3}{*}{4} & & \begin{tabular}{l|l}
7 \\
\end{tabular} & 2 & 8 & \begin{tabular}{l|l}
1 & 10 \\
\end{tabular} & & 1 & \\
\hline & 2 & 2 & 3 & & \begin{tabular}{l|l}
10 & 3
\end{tabular} & $\begin{array}{l}0 \\
3\end{array}$ & & & & \begin{tabular}{l|l}
10 & 1 \\
\end{tabular} & \begin{tabular}{l|l}
15 & 12 \\
\end{tabular} & \begin{tabular}{l|l|l}
2 & 22 \\
\end{tabular} & 21 & 8 & 4 \\
\hline & \begin{tabular}{l|l}
2 \\
2
\end{tabular} & & & & \begin{tabular}{l|l}
10 \\
4 & 3 \\
\end{tabular} & & & \multicolumn{8}{|l|}{ Cell wall organization } \\
\hline \multicolumn{8}{|l|}{ Disease resistance proteins } & Endoglucanase & 2 & 4 & & 11 & 2 & & 1 \\
\hline \multirow{5}{*}{$\begin{array}{l}\text { Disease resistance protein RGA } \\
\text { Disease resistance protein RPM } \\
\text { Disease resistance RPP } \\
\text { Pleiotropic drug resistance protein }\end{array}$} & 4 & 4 & 1 & 1 & 5 & & \multirow{2}{*}{3} & Chitinase/endochitinase & 9 & 3 & 1 & 5 & & & 1 \\
\hline & 6 & 4 & 2 & 1 & 1 & & & Glucan endo-1,3-beta-glucosidase & 4 & 6 & 6 & & 5 & 2 & 1 \\
\hline & 3 & 3 & 2 & & $\frac{1}{3}$ & 1 & 1 & Xyloglucan endotransglucosylase & $17 \mid 1$ & 12 & 2 & 16 & 9 & & 2 \\
\hline & $\frac{3}{2}$ & & $\frac{2}{2}$ & 1 & \begin{tabular}{r|l}
3 & \\
1 & 1
\end{tabular} & 1 & & Polygalacturonase & 5 & 3 & 1 & 21 & 3 & 1 & 2 \\
\hline \multirow{2}{*}{\multicolumn{8}{|c|}{ Secondary metabolism-related genes }} & Pectinesterase & 3 & 2 & 4 & 14 & 3 & & \\
\hline & & & & & & & & Cellulose synthase & 5 & 4 & 3 & 6 & 1 & & \\
\hline \multirow{8}{*}{$\begin{array}{l}\text { Flavonol synthase } \\
\text { Caffeic acid 3-O-methyltransferase } \\
\text { Caffeoylshikimate esterase } \\
\text { Caffeoyl-CoA O-methyltransferase } \\
\text { Isoflavone 2'-hydroxylase-like } \\
\text { Isoflavone reductase } \\
\text { S-adenosylmethionine synthase } \\
\end{array}$} & & 1 & 2 & & 2 & 1 & & Glucuronosyltransferase & 3 & 3 & 2 & 6 & 5 & & \\
\hline & 2 & & & & \begin{tabular}{l|l}
1 & \\
\end{tabular} & & & Xyloglucan glycosyltransferase & 1 & 5 & 1 & 6 & 5 & & \\
\hline & 2 & 2 & 1 & & \begin{tabular}{l|l|}
1 & 1 \\
\end{tabular} & & & Galacturonosyl transferase & \begin{tabular}{l|l}
4 \\
\end{tabular} & 6 & 1 & 19 & 3 & & \\
\hline & 1 & & 2 & & & & & Leucine-rich repeat extensin protein & 1 & & 4 & 6 & 2 & & \\
\hline & 3 & & & 1 & & & 1 & Expansin & \begin{tabular}{|l|l}
4 & 0 \\
\end{tabular} & 2 & & $2 \mid 22$ & \begin{tabular}{|l|l|}
2 & 4 \\
\end{tabular} & & 4 \\
\hline & & & & & 2 & & & \multirow{3}{*}{\multicolumn{5}{|c|}{$\begin{aligned} \text { No. of DEGs: } & 1 \\
& \text { from } 2 \text { to } 8 \\
& \text { from } 9 \text { to } 15 \\
& \text { from } 16 \text { to } 22 \\
& \geq 23\end{aligned}$}} & & & \\
\hline & & 2 & 3 & & 2 & & & & & & & & & & \\
\hline & & & & & & & & & & & & & & & \\
\hline
\end{tabular}

Interestingly, the numbers of up-regulated and downregulated genes were similar at $1 \mathrm{dpt}$ in leaves, while for roots, a greater number of BTH-induced than repressed genes at $1 \mathrm{dpt}$ (Fig. 6, Additional file 7: Table S6). These genes with significantly changed abundance might be related to disease defense and could lead to a better understanding of the mechanisms involved in BTH-induced Foc 4 responses.

\section{Secondary metabolism-related genes modulated by BTH}

Some enzymes associated with secondary metabolism play key roles in the synthesis of antifungal compounds and cell wall components, which are involved in the phenylpropanoid pathway and other pathways. In our study, more than 27 DEGs involved in the phenylpropanoid and other secondary metabolism pathways were modulated by $\mathrm{BTH}$, such as flavonol synthase caffeic acid (FLS), caffeic acid 3-O-methyltransferase (COMT), caffeoyl-CoA O-methyltransferase (CCOMT), caffeoylshikimate esterase (CSE), isoflavone reductase (IFR) and leucoanthocyanidin dioxygenase (LDOX) (Fig. 6, Additional file 7: Table S6). COMT, CCOMT and CSE are associated with lignin biosynthesis, which is beneficial for the lignification of the cell wall in response to pathogen infection. Several these enzymes, such as Ma11G07580, Ma10G26780 and MarG09770 were intensely up-regulated by BTH. The IFR was mainly involved in catalyzing the synthesis of isoflavonoid phytoalexin medicarpin, and was found to be rapidly induced in response to fungal pathogen infection in alfalfa [61]. We identified two IFRs (Ma2G14320 and Ma4G24530) were induced by BTH in roots (Fig. 6, Additional file 7: Table S6). S-adenosylmethionine synthase $(S A M)$ plays an essential role in plant defense via catalyzing the production of S-adenosyl-L-methionine, which supplies as a methyl-group donor in the biosynthesis of numerous secondary metabolites. SAMs were observed to be down-regulated in leaves at $1 \mathrm{dpt}$, but were restored at $3 \mathrm{dpt}$. Whereas, at $1 \mathrm{dpt}, S A M s$ were mainly up-regulated by BTH in roots (Fig. 6, Additional file 7: Table S6). These results indicated that a wide range of enzymes participated in secondary metabolism pathways were induced by BTH, and their products may be contributed to $\mathrm{BTH}$-dependent pathogen resistance. 


\section{ROS metabolism-related genes that function in BTH response}

In terms of ROS scavenging genes, a significant increase of peroxidases and polyphenol oxidases was observed at all time points in both leaves and roots (Fig. 6, Additional file 7: Table S6). Moreover, at $1 \mathrm{dpt}$, BTH induced up-regulation of a larger number of peroxidases in roots than in leaves. Among these DEGs, three peroxidases Ma6G21980, Ma9G30170 and Ma5G15750 were strongly up-regulated at $1 \mathrm{dpt}$ in roots (Fold change > 100). Additionally, DEGs responsible for cell detoxification, such as THIOREDOXIN (TRX), GLUTAREDOXIN $(G R X)$, L-ascorbate oxidase (ASOD), L-ascorbate peroxidase $(A P X)$ and glutathione s-transferase (GST) genes were differently modulated by BTH in the two tissues. Approximately $21.2 \%$ of up-regulated DEGs in roots exhibited a different expression pattern in leaves, where they were mainly suppressed by BTH. For example, the TRX genes Ma10G21720 and Ma3G25160 were up-regulated at $1 \mathrm{dpt}$ and $3 \mathrm{dpt}$ in roots (Fold change = 5.7 to 145.2), but were down-regulated in leaves. In roots, BTH primarily induced the majority of these DEGs at $1 \mathrm{dpt}$. However, a different trend was observed in leaves, as the numbers of up-regulated and down-regulated DEGs were similar (Fig. 6). The increases in the abundances of peroxidases, TRXs, GRXs and GSTs indicated a possible up-regulation of ROS scavenging capacity in banana plants under BTH treatment.

\section{Cell wall organization in BTH treatment}

The plant cell wall acts as an important barrier against pathogen penetration into the intracellular space in plants [62]. Plant primary cell walls are mainly composed of polysaccharide such as pectins, celluloses and hemicelluloses, whereas secondary walls contain additional compounds such as lignins, cutin or wax [63]. Extensive research has revealed that activation of cell wall strengthening-related gene and induction of fungal cell wall degrading enzymes helps to inhibit pathogen entry [62]. In this study, BTH-treatment of banana plants induces the accumulation of a wide variety of proteins that are involved in cell wall metabolism at different levels in both leaves and roots, from remodeling and reinforcing of the plant cell wall to degradation of the pathogen itself. Among 254 DEGs responsible for cell wall organization, the endoglucanase, chitinase and glucan endo-1,3-beta-glucosidase associated with cell wall hydrolysis, and the xyloglucan endotransglucosylase (XTH), polygalacturonase, pectinesterase, cellulose synthase, galacturonosyl transferase and expansin involved in cell wall modification or maintenance were significantly modulated by BTH (Fig. 6, Additional file 7: Table S6). In particular, the abundance of most of these enzymes such as polygalacturonase and glucan endo-1, 3-beta-glu cosidase, was found to be mainly accumulated in roots at $1 \mathrm{dpt}$ (Fold change $=2.6$ to 200.1), and only a few of these genes were affected at $3 \mathrm{dpt}$. In contrast, the numbers of up-regulated genes at $1 \mathrm{dpt}$ and $3 \mathrm{dpt}$ in leaves were similar (Fig. 6, Additional file 7: Table S6). The overall view for the cell wall metabolism genes showed a greater number of up-regulated than down-regulated genes at all time points. The result obtained implies that cell wall strengthening through structurally and chemically, especially in roots, may contribute to BTH-induced pathogen resistance in banana.

\section{Verification of the gene expression profiles by qRT-PCR}

To verify the expression profiles of the genes in our analyses, we selected 6 DEGs for qRT-PCR using samples of leaves and roots originally used for RNA-Seq, which included the genes encoding MaLRR-RLK (Ma5G15040), MaARF (Ma4G22520), MaERF (Ma10G04450), MaMCM8 (Ma11G08430), PR proteins (Ma9G16540) and RGA1 (Ma6G19890). As shown in Fig. 7, all 6 genes showed the similar expression pattern as the in banana differential analysis results from RNA-Seq data. These DEGs were selected for their potentially key roles in regulating BTH signal transcription and pathogen response. For example, responses to biotic stimuli in Arabidopsis have often been reported to be associated with increased accumulation of transcripts encoding LRR-RLK proteins. Brassinos teroid insensitive 1-associated receptor kinase 1 (BAK1) constituted one of the best studied plant LRR-RLK, and was shown to function as pattern recognition receptors mediating the recognition of microbial surface structures [64]. Additionally, the RGA proteins encoded by the majority of $R$ genes represent important intracellular receptors that play specific roles in pathogens' resistance [65]. Overexpression of pathogen-induced grapevine VaRGA1 gene enhances disease resistance and abiotic stresses tolerance in $\mathrm{Ni}$ cotiana benthamian [66]. The results showed that four genes were remarkably highly expressed in roots at $1 \mathrm{dpt}$, including MaLRR-RLK, MaARF, MaMCM8 and MaRGA1 (Fig. 7a, b, d and f), indicating their signal perception and transcription reactions after receiving the $\mathrm{BTH}$ signal. MaERF gene was more highly expressed at $3 \mathrm{dpt}$ in the both leaves and roots (Fig. 7c), demonstrating that this gene may react slowly after BTH treatment. On the contrary, the expression level of the $P R$ gene was higher in leaves at 1 and $3 \mathrm{dpt}$ than in roots (Fig. 7e). The PR genes encode a class of proteins that suppress pathogens, detoxify toxins or virulence factors produced by pathogens and prevent pathogen advancement by enforcing plant cell walls. In Nicotiana tabacum, overexpression of NtPR-Q gene up-regulates multiple defense-related genes and enhances plant resistance 

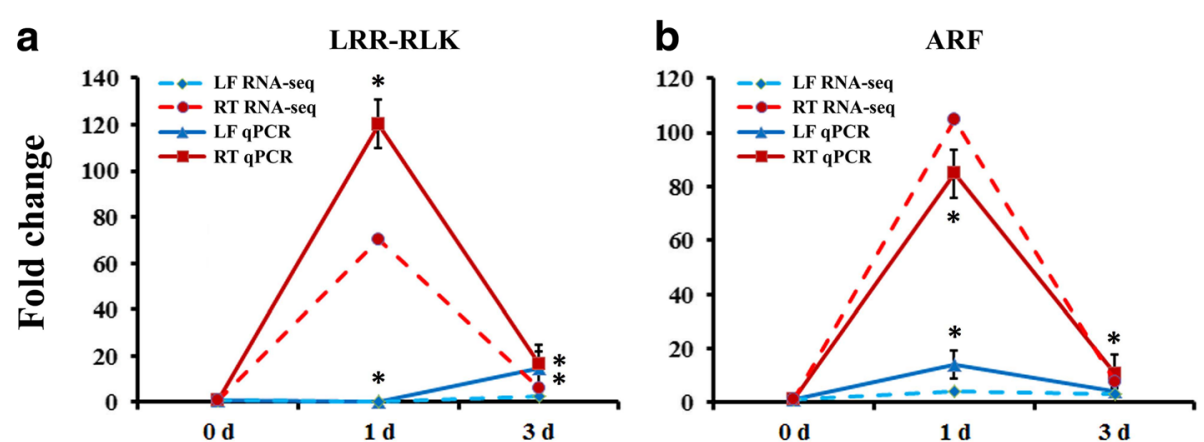

C

ERF
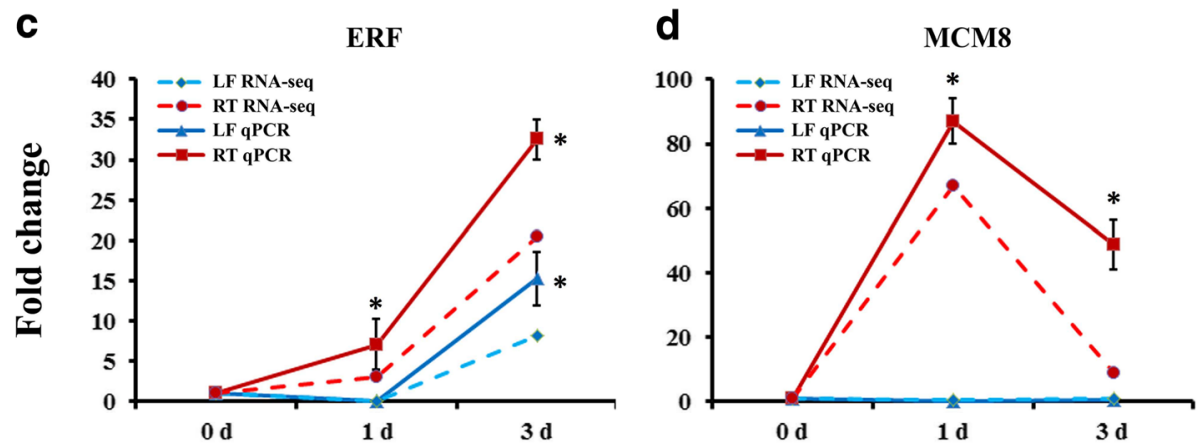

e

PR

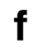

RGA1
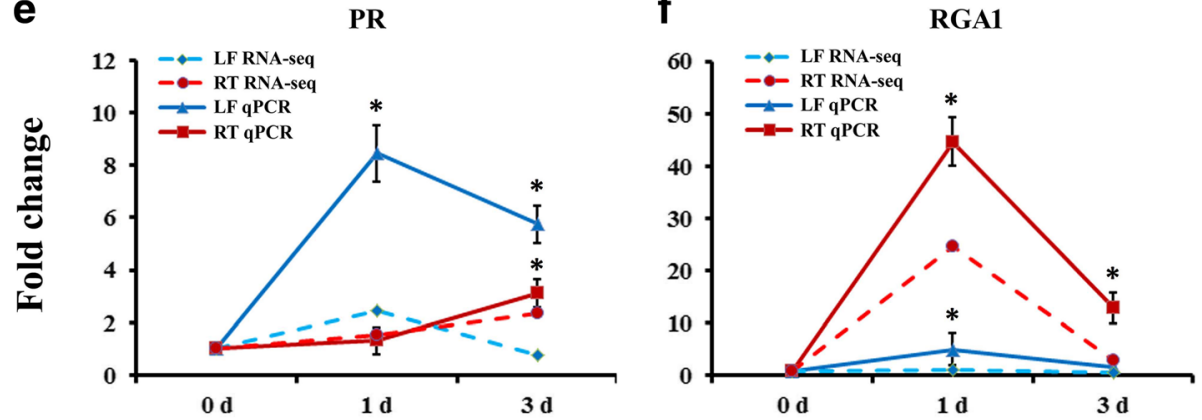

Fig. 7 The expression profiles of 6 genes in banana leaves and roots by the quantitative RT-PCR. a-f The expression patterns of DEGs under BTH treatment by qPCR and RNA-Seq, respectively. MaACTIN was used as the reference gene. Data are presented as means \pm SD of three independent assays. The asterisks indicate significant differences compared with the control treatment, ${ }^{*} P<0.01$ by Student's t-test. LF, leaf; RT, root

to Ralstonia solanacearum [67]. Taken together, the results suggested that these genes might be involved in BTH-induced defense reactions of banana to Foc 4. Thus, the functions of these genes in banana should be further investigated in the future studies.

\section{Discussion}

Two groups of BTH have been recognized as plant protection agents for a number of pathogens by inducing the plant's own defense mechanisms in many plant species [18, 33-35]. Previously studies revealed that the plant resistance-inducing ability of $\mathrm{BTH}$ is based on mimicking the biological activation of SAR [34, 35]. In the present study, for the first time, we observed that the BTH-sprayed banana plants behave as more resistant to Foc 4 infection than unsprayed plants, without any direct toxic effect on plants growth and development. The primary goal of this study was to elucidate the defense mechanisms induced by BTH through investigating whole transcriptional changes of banana leaves and roots under control and BTH treatment. The RNA-Seq analysis carried out at 1 and $3 \mathrm{dpt}$ of leaves and roots revealed that 6689 and 3624 genes were differentially modulated by BTH, respectively, as compared to the control. However, at all-time points, less than $12.4 \%$ of the DEGs were affected in both leaves and roots, and within each tested tissue, less than $9.8 \%$ of the DEGs were modulated at all of the times analyzed. This result indicated the excessive variability of such gene modulation over time and among tissues. After further functional classification of these DEGs, we observed that the defense responses were more dramatic in the roots than 
in the leaves. For example, enrichment analyses revealed the involvement of DEGs associated with the auxin signaling responses, cell cycle regulation, cell wall metabolism and defense signaling, were induced more intensely in the roots. This difference in genes expression was further supported by the change of the TFs activity and the change of RLKs content in the two tissues after BTH treatment. The results presented here have highlighted key processes that might further studied to improve BTH-induced resistance against Foc 4 infection, and also provided us with new tools with which to improve the disease resistance of banana and other plants.

Plant hormones such as SA, JA, auxin and ET, are well-known to play critical roles in plant-fungal interactions [14]. In general, SA and JA accumulation and signaling positively regulate defense to plant pathogenic fungi in a wide range of tested plants [16, 20, 68, 69]. ET signaling can either reduce or enhance disease symptoms caused by pathogen infection in an age-and/or condition-dependent manner among different species [14, 69]. In contrast, $F$. oxysporum-inoculated auxin-signaling or transport Arabidopsis mutants displayed prominently reduced symptoms compared to control plants, suggesting that local alterations of auxin levels are essential for $F$. oxysporum colonization [28]. Transcriptomic data obtained in this study revealed that the core auxin-signaling component such as YUCCAs, auxin efflux carriers (PINs) and ARFs were induced in root especially at the relatively early time points analyzed. Additionally, the expression levels of ACC synthases (ACSs), ethylene receptors (ERSs), EIN3-binding F-box protein $(E B F s)$ and ERFs were significantly increased in leaves. An interesting feature about the activation by BTH was the differential tissue-specific response. Briefly, DEGs associated with ET signaling pathway were primarily modulated by BTH in leaves, whereas DEGs participate in auxin biosynthesis, transport and response were mainly induced in a root-specific manner. Previously studies on transcriptomic analysis of Foc 4 infected banana roots have revealed the differential expression of JA- and ET-related genes, but SA and auxin marker genes were unaffected [11,37], indicating that in banana defense against Foc 4 is predominantly mediated via ET/JA signaling. In our study, transcriptome profiling of banana leaves and roots failed to detect activation of typical SA and JA marker genes in response to BTH, which is partially consistent with the previous researches $[11,32,38]$. These results led to the suggestion that BTH-induced Foc 4 resistance in banana was dependent on auxin and ET signals. However, how exactly BTH manipulates auxin and ET signaling in a tissue-specific manner remains to be addressed in the future.

In response to pathogen infection, plants develop systemic acquired resistance (SAR), a state of preparedness that provides elevated resistance during subsequent infections [70]. Besides pathogens, SA and its chemical analogs such as BTH are capable of inducing SAR in plants $[34,35]$. Previously studies identified a number of compounds such as SA, JA, methyl salicylate, dihydroabetinal, azelaic acid, glycerol-3-phosphate, PR proteins and lipid transfer protein DIR1 as potential mobile signals of SAR [71, 72]. In BTH-sprayed banana roots, several thaumatin-like proteins (TLPs) genes and lipid transfer proteins (LTPS) were intensely induced at early stage of treatment. TLPs affect the fungus growth with $\beta$-glucanase and xylanase inhibitor activities, and have been reported against a variety of filamentous fungal pathogen [73]. Overexpression of TLP genes in transgenic plants have shown enhanced resistance and protection against different fungal pathogens [74]. Lipid transfer protein genes have also been shown to enhance plants resistance to trichothecene mycotoxin, in Arabidopsis thaliana and in Saccharomyces cerevisiae [75]. Additionally, genes encoding for nucleotide binding (NB)-leucine-rich repeat (LRR) disease resistance proteins ( $R$ proteins) such as RGA, RPM and RPP were found to be accumulated in both leaves and roots. $R$ proteins have conserved domains and motifs that play specific roles in recognizing pathogens and activating inducible defenses. As these genes are associated to trigger disease resistance in various species, their enrichment amongst up-regulated genes might reflect traces of an enhanced immune response to Foc 4 infection of the BTH-treated plants.

The plant cell wall provides a structural framework to support plant growth and acts as a pathological and environmental barrier that defends against pathogens. Typical components of the cell wall include pectins, cellulose, hemicelluloses, lignins, proteins and water [63]. In response to an attack, plants deposit certain reinforcing polymers which may cause plant cell wall modification, and release degradation fragments to disturb fungal cell wall integrity [62]. Notably, in the present study, a great number of genes involved in cell wall metabolism including endoglucanase, chitinase, glucan endo-1,3-beta -glucosidase, polygalacturonase, pectinesterase, cellulose synthase, XTHs, galacturonosyl transferase and expansins were found to increase in BTH-treated banana plants. It should be mentioned that chitinases and glucanases represent two large apoplastic protein families which are known to limit fungal growth via the degradation of the glucans from fungal cell walls [62]. Previous study has shown specific changes in the cell wall modification-related genes through transcriptomic and proteomic methods after the application of a specific biotic stress, and hypothesized that cell wall components may influence the interaction of pathogen and host. For instance, Verticillium longisporum infection of Arabidopsis leads to a specific increase of 


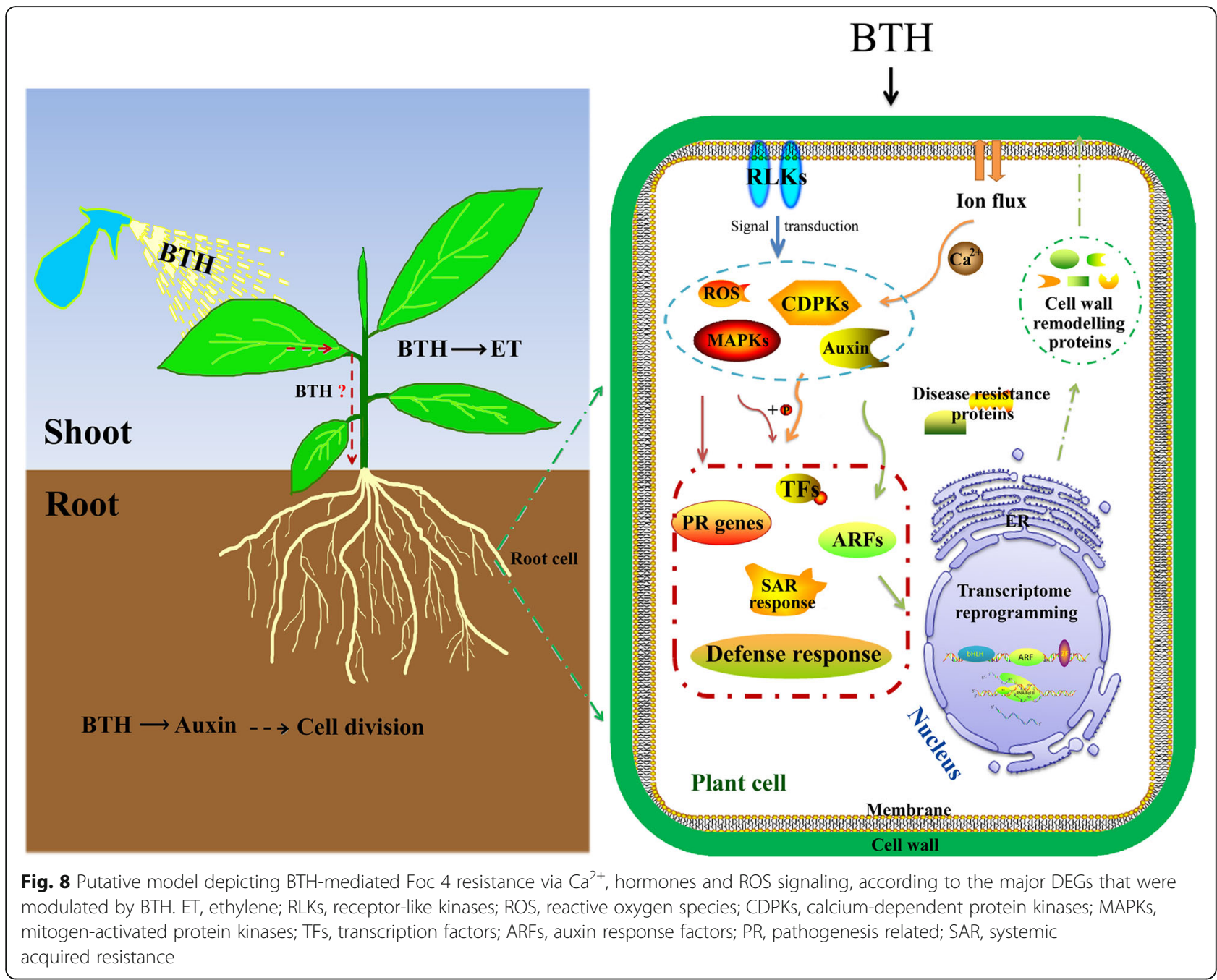

several extracellular proteins which mainly function in defense and cell wall metabolism [76]. The agroinfiltration of tobacco plants also results in the accumulation of a number of cell wall-modifying enzymes [77]. These results are consistent with similar findings for BTH-treated banana plants and might be common in plant pathogenesis. Early study also revealed that modified cell wall composition can indeed result in altered disease resistance phenotypes in host banana [78]. Therefore, the increase in the abundance of cell wall organization enzymes might explain the significant enhanced Foc 4 resistance after BTH treatment in banana.

RLKs play essential roles in plant immunity and development [49]. Plants employ a large number of RLKs as PRRs that detect PAMPs as the first layer of inducible defense [79]. In this study, a total of 107 and 124 RLK genes were induced in the leaves and roots of BTH-sprayed banana plants, respectively. Among these genes, 37 RLKs were mainly up-regulated in leaves, including 6 WAKL-, 4 cysteine-rich RLK-, 23 L/G-type lectin receptor kinase- and 4 lysM domain RLK-related genes. However, the other four types RLKs, which contain 6 serine/threonine receptor kinases, 25 receptor-like protein kinases, 78 LRR-RLKs and 6 proline-rich RLKs, were primarily elevated in roots. Previously, $Z m W A K$, which encodes a maize wall-associated kinase gene and confers quantitative resistance to head smut, was isolated by map-based cloning [80]. Lectin-RLKs are uniquely essential for plant disease resistance [49]. The Arabidopsis lectin S-domain-1 receptor-like kinase (LORE) acts as a receptor in sensing the lipid A moiety of bacterial LPSs (lipopolysaccharides), and contributes to plant immunity in response to bacteria [81]. LysM domain-RLKs represent a key class of receptors for microbial $\mathrm{N}$-acetylglucosamine-containing glycans, which generally trigger defenses. A large portion of Arabidopsis LysM-RLKs have been shown to be essential for chitin-induced defenses in plants [49]. LRR-RLKs comprise the largest subgroup within the RLK superfamily in plants. Functional analysis of LRR-RLKs indicates that 
the majority of them function as regulators of defense response to viral, bacterial pathogen and necrotrophic fungus infection [49]. Therefore, the BTH-induced RLKs (particularly in roots) might play important roles in recognizing PAMPs produced by Foc 4 and in triggering defense responses.

Taken together, comparative analyses of transcriptomic data suggest that a different initial impact of BTH on shoots and roots (Fig. 8). More specifically, when BTH is applied to banana leaves, it primarily induces ET biosynthesis and response genes in leaves. Then, the BTH is somehow transported to the roots where the auxin signaling-related genes are uniquely up-regulated. The auxin signaling may subsequently affect cell division in roots, as underlined by the results of the enrichment analysis. We have highlighted in Fig. 8 the predominant influence of BTH on banana roots, considering that the soil-borne fungus Foc 4 mainly infects banana roots. The BTH-induced signals are perceived by membrane-located receptors, followed by hormones and $\mathrm{Ca}^{2+}$ transduction to activate downstream responsive genes, including TFs, PR genes, disease resistance and SAR-related genes. Furthermore, BTH altered the concentration of $\mathrm{Ca}^{2+}$ and ROS in the cytoplasm and elevated a series of ROS homeostasis related genes. The significantly altered TFs, such as $b H L H s, A R F s$ and $Z F s$ activate the expression of cell wall remodeling proteins, which may further affect cell wall organization and form a physical barrier that results in decreased Foc 4 infection.

\section{Conclusion}

The current study delineates BTH-mediated endogenous biotic defense mechanisms adapted by banana plants under Foc 4 infection. A large number of DEGs associated with signal transduction, transcription activation/ repression, disease resistant and ROS/hormone signaling pathways were identified in leaves and roots of BTH-sprayed plants. More importantly, the unique positive impacts of $\mathrm{BTH}$ on the cell cycle process and cell wall organization in roots haves also been observed. This ultimately may help to modify the structure of plant cell wall, which attributes a key role to protect plant roots from Foc 4 infection. Taking such insights into account, The DEGs identified in the present study could provide a resource for further developing resistant varieties against Foc 4 infection.

\section{Additional files}

Additional file 1: Table S7. Gene-specific primers used for QRT-PCR (XLSX $10 \mathrm{~kb}$ )

Additional file 2: Table S1. The information of 3996 identified banana novel protein-coding transcripts in the study. (XLSX $4797 \mathrm{~kb}$ )
Additional file 3: Table S2a. Expression information of DEGs in leaves at 1 day after BTH treatment. Table S2b. Expression information of DEGs in leaves at 3 day after BTH treatment. Table S2c. Expression information of DEGs in roots at 1 day after BTH treatment. Table S2d. Expression information of DEGs in roots at 3 day after BTH treatment. (XLSX $2340 \mathrm{~kb}$ )

Additional file 4: Table S3. GO terms of biological process enriched in banana leaves and roots. (XLSX $29 \mathrm{~kb}$ )

Additional file 5: Table S4. The significantly enriched pathways of DEGs in banana leaves and roots. (XLSX $11 \mathrm{~kb}$ )

Additional file 6: Table S5. Differentially expressed genes involved in protein kinases and transcription factors. (XLSX $225 \mathrm{~kb}$ )

Additional file 7: Table S6. Expression information of DEGs in Figs. 5 and 6. (XLSX $123 \mathrm{~kb})$

\section{Abbreviations}

ABA: Abscisic acid; ANOVA: One-way analysis of variance; AP2/ERF: APETALA 2/Ethylene-Responsive Factor; APX: Ascorbate peroxidase; ARF: Auxin response factor; ASOD: Ascorbate oxidase; BABA: $\beta$-aminobutyric acid; bHLH: Basic helix-loop-helix; BTH: Benzothiadiazole; Ca2+: Calcium; CCOMT: Caffeoyl-CoA O-methyltransferase; Cdc20: Cell division cycle 20; CDNA: Complementary DNA; CDPKs: Calcium dependent protein kinases; COI1: Coronatine-Insensitive 1; COMT: Caffeic acid 3-O-methyltransferase; CSE: Caffeoylshikimate esterase; DEGs: Differentially expressed genes; DIR1: Defective in induced resistance 1; EBF: EIN3-binding F-box proteins; EIN2: Ethylene-insensitive 2; ERFs: Ethylene response factors; ET: Ethylene; ETI: Effector-triggered immunity; ETR1: Ethylene receptor 1; FDR: False discovery rate; FLS: Flavonol synthase caffeic acid; Foc 4: Fusarium oxysporum f. sp. cubense tropical race 4; FPKM: Fragments per kb exon model per million mapped fragments; GO: Gene ontology; GRX: Glutaredoxin; GST: Glutathione s-transferase; HR: Hypersensitive response; IFR: Isoflavone reductase; JA: Jasmonic acid; KEGG: Kyoto encyclopedia of genes and genomes; LDOX: Leucoanthocyanidin dioxygenase; LORE: Lectin S-domain-1 receptor-like kinase;

LPSS: Lipopolysaccharides; LRR: Leucine-rich repeat; LTPs: Lipid transfer proteins; MADs: Mitotic spindle checkpoint proteins; MAPKs: Mitogenactivated protein kinases; NCBI: National center for biotechnology information; NPR1: Non-expression of pathogenesis related gene 1; Orc: Origin recognition complex subunits; PAMP: Pathogen-associated molecular pattern; PCNA: Proliferating cell nuclear antigen; PR: Pathogenesisrelated; PRIs: Plant resistance inducers; PRR: Pattern recognition receptor; PTI: PAMP-triggered immunity; qRT-PCR: Quantitative real-time polymerase chain reaction; R protein: Disease-resistance protein; RLKs: Receptor-like kinases; RNA-Seq: Ribonucleic acid sequencing; ROS: Reactive oxygen species; SA: Salicylic acid; SAM: S-adenosylmethionine synthase; SAR: Systemic acquired resistance; SPL: Squamosa promoter binding-like protein; TFs: Transcription factors; TLPS: Thaumatin-like proteins;

TRX: Thioredoxin; WAK: Wall-associated kinase; XTH: Xyloglucan endotransglucosylase; ZF: Zinc finger

\section{Acknowledgements}

We thank Dr. Liangsheng Zhang for helpful comments on this manuscript. We also thank Dr. Chunqiang Li for providing the Foc 4 strain.

\section{Funding}

This work was supported by the National Natural Science Foundation of China (31701903 and 31701484). The funding body has no role in study design, data collection and analysis, or preparation of the manuscript.

\section{Availability of data and materials}

All raw RNA-Seq read data used in this work are available from the NCBI SRA database, under the BioProject PRJNA417328, with 18 accession numbers: SRR6311404-421, inclusive.

\section{Authors' contributions}

ZHC and QW participated in the design of the study. ZHC, XY and SXL analyzed the RNA-Seq data. All authors read and approved the final manuscript. 


\section{Ethics approval and consent to participate}

No ethics approval was required for the conduct of experiments in this study. The banana cultivar (Musa spp.; AAA Group; Brazil) used in this study is acquired from Tropical Crops Genetic Resources Institute, Chinese Academy of Tropical Agricultural Sciences, Danzhou of China.

\section{Competing interests}

The authors declare that they have no competing interests.

\section{Publisher's Note}

Springer Nature remains neutral with regard to jurisdictional claims in published maps and institutional affiliations.

\section{Author details}

${ }^{1}$ Haikou Experimental Station, Chinese Academy of Tropical Agricultural Sciences, Haikou 570102, China. ${ }^{2}$ Department of Biology, University of Pennsylvania, Philadelphia, PA 19104, USA. ${ }^{3}$ Institute of Tropical Bioscience and Biotechnology, Chinese Academy of Tropical Agricultural Sciences, Haikou 571101, China.

\section{Received: 30 November 2017 Accepted: 25 May 2018}

\section{Published online: 13 June 2018}

\section{References}

1. Dodds PN, Rathjen JP. Plant immunity: towards an integrated view of plantpathogen interactions. Nat Rev Genet. 2010;11(8):539-48.

2. Swarupa $\mathrm{V}$, Ravishankar KV, Rekha A. Plant defense response against fusarium oxysporum and strategies to develop tolerant genotypes in banana. Planta. 2014;239(4):735-51.

3. Jones JD, Dangl JL. The plant immune system. Nature. 2006;444(7117):323-9.

4. Wurzinger B, Mair A, Pfister B, Teige M. Cross-talk of calcium-dependent protein kinase and MAP kinase signaling. Plant Signal Behav. 2011;6(1):8-12.

5. Boudsocq M, Willmann MR, McCormack M, Lee H, Shan L, He P, Bush J, Cheng $\mathrm{SH}$, Sheen J. Differential innate immune signalling via $\mathrm{Ca}(2+)$ sensor protein kinases. Nature. 2010;464(7287):418-22.

6. Galletti R, Ferrari S, De Lorenzo G. Arabidopsis MPK3 and MPK6 play different roles in basal and oligogalacturonide- or flagellin-induced resistance against Botrytis cinerea. Plant Physiol. 2011;157(2):804-14.

7. Bethke G, Unthan T, Uhrig JF, Poschl Y, Gust AA, Scheel D, Lee J. Flg22 regulates the release of an ethylene response factor substrate from MAP kinase 6 in Arabidopsis thaliana via ethylene signaling. Proc Natl Acad Sci U S A. 2009;106(19):8067-72.

8. Sheikh AH, Eschen-Lippold L, Pecher P, Hoehenwarter W, Sinha AK, Scheel D, Lee J. Regulation of WRKY46 transcription factor function by mitogenactivated protein kinases in Arabidopsis thaliana. Front Plant Sci. 2016;7:61.

9. Wu J, Zhao Q, Yang Q, Liu H, Li Q, Yi X, Cheng Y, Guo L, Fan C, Zhou Y. Comparative transcriptomic analysis uncovers the complex genetic network for resistance to Sclerotinia sclerotiorum in Brassica napus. Sci Rep. 2016:6:19007.

10. Torres MA, Jones JD, Dangl JL. Reactive oxygen species signaling in response to pathogens. Plant Physiol. 2006;141(2):373-8.

11. Li CY, Deng GM, Yang J, Viljoen A, Jin Y, Kuang RB, Zuo CW, Lv ZC, Yang QS, Sheng $\mathrm{O}$, et al. Transcriptome profiling of resistant and susceptible Cavendish banana roots following inoculation with fusarium oxysporum $\mathrm{f}$. Sp. cubense tropical race 4. BMC Genomics. 2012;13:374.

12. Yang $D L$, Yang $Y$, He $Z$. Roles of plant hormones and their interplay in rice immunity. Mol Plant. 2013;6(3):675-85

13. Alazem M, Lin NS. Roles of plant hormones in the regulation of host-virus interactions. Mol Plant Pathol. 2015;16(5):529-40.

14. Di X, Takken FL, Tintor N. How phytohormones shape interactions between plants and the soil-borne fungus fusarium oxysporum. Front Plant Sci. 2016; 7:170.

15. Vlot AC, Dempsey DA, Klessig DF. Salicylic acid, a multifaceted hormone to combat disease. Annu Rev Phytopathol. 2009;47:177-206.

16. Wang Z, Jia C, Li J, Huang S, Xu B, Jin Z. Activation of salicylic acid metabolism and signal transduction can enhance resistance to fusarium wilt in banana (Musa acuminata L. AAA group, cv. Cavendish). Funct Integr Genomics. 2015;15(1):47-62.

17. Jogaiah S, Abdelrahman M, Tran LP, Ito SI. Different mechanisms of Trichoderma virens-mediated resistance in tomato against fusarium wilt involve the jasmonic and salicylic acid pathways. Mol Plant Pathol. 2017; 19(4):870-82.
18. Bovie C, Ongena M, Thonart P, Dommes J. Cloning and expression analysis of cDNAs corresponding to genes activated in cucumber showing systemic acquired resistance after BTH treatment. BMC Plant Biol. 2004;4:15.

19. Underwood J, Moch J, Chen MS, Zhu L. Exogenous salicylic acid enhances the resistance of wheat seedlings to hessian fly (Diptera: Cecidomyiidae) infestation under heat stress. J Econ Entomol. 2014;107(5):2000-4.

20. Mandal S, Mallick N, Mitra A. Salicylic acid-induced resistance to fusarium oxysporum f. Sp. lycopersici in tomato. Plant Physiol Biochem. 2009;47(7):642-9.

21. Mayers CN, Lee KC, Moore CA, Wong SM, Carr JP. Salicylic acid-induced resistance to cucumber mosaic virus in squash and Arabidopsis thaliana: contrasting mechanisms of induction and antiviral action. Mol Plant Microbe Interact. 2005;18(5):428-34

22. Endah R, Beyene G, Kiggundu A, van den Berg N, Schluter U, Kunert K, Chikwamba R. Elicitor and fusarium-induced expression of NPR1-like genes in banana. Plant Physiol Biochem. 2008:46(11):1007-14.

23. Trusov Y, Sewelam N, Rookes JE, Kunkel M, Nowak E, Schenk PM, Botella JR. Heterotrimeric $\mathrm{G}$ proteins-mediated resistance to necrotrophic pathogens includes mechanisms independent of salicylic acid-, jasmonic acid/ethyleneand abscisic acid-mediated defense signaling. Plant J. 2009;58(1):69-81.

24. Pantelides IS, Tjamos SE, Pappa S, Kargakis M, Paplomatas EJ. The ethylene receptor ETR1 is required for fusarium oxysporum pathogenicity. Plant Pathol. 2013;62(6):1302-9.

25. Thatcher LF, Manners JM, Kazan K. Fusarium oxysporum hijacks COI1mediated jasmonate signaling to promote disease development in Arabidopsis. Plant J. 2009:58(6):927-39.

26. Yang C, Li L. Hormonal regulation in shade avoidance. Front Plant Sci. 2017;8:1527.

27. Xu L. De novo root regeneration from leaf explants: wounding, auxin, and cell fate transition Curr Opin Plant Biol. 2017:41·39-45.

28. Kidd BN, Kadoo NY, Dombrecht B, Tekeoglu M, Gardiner DM, Thatcher LF, Aitken EA, Schenk PM, Manners JM, Kazan K. Auxin signaling and transport promote susceptibility to the root-infecting fungal pathogen fusarium oxysporum in Arabidopsis. Mol Plant Microbe Interact. 2011;24(6):733-48.

29. Kazan K, Manners JM. Linking development to defense: auxin in plantpathogen interactions. Trends Plant Sci. 2009;14(7):373-82.

30. Ploetz RC. Fusarium wilt of banana. Phytopathology. 2015;105(12):1512-21

31. De Ascensao AR, Dubery IA. Panama disease: Cell Wall reinforcement in banana roots in response to elicitors from fusarium oxysporum f. Sp. cubense race four. Phytopathology. 2000:90(10):1173-80.

32. Li C, Shao J, Wang Y, Li W, Guo D, Yan B, Xia Y, Peng M. Analysis of banana transcriptome and global gene expression profiles in banana roots in response to infection by race 1 and tropical race 4 of fusarium oxysporum $f$. Sp. cubense. BMC Genomics. 2013;14:851.

33. Alexandersson E, Mulugeta T, Lankinen A, Liljeroth E, Andreasson E. Plant resistance inducers against pathogens in Solanaceae species-from molecular mechanisms to field application. Int J Mol Sci. 2016;17(10):1673.

34. Gorlach J, Volrath S, Knauf-Beiter G, Hengy G, Beckhove U, Kogel KH, Oostendorp M, Staub T, Ward E, Kessmann H, et al. Benzothiadiazole, a novel class of inducers of systemic acquired resistance, activates gene expression and disease resistance in wheat. Plant Cell. 1996;8(4):629-43.

35. Lawton KA, Friedrich L, Hunt M, Weymann K, Delaney T, Kessmann H, Staub T, Ryals J. Benzothiadiazole induces disease resistance in Arabidopsis by activation of the systemic acquired resistance signal transduction pathway. Plant J. 1996:10(1):71-82

36. Wang Z, Zhang J, Jia C, Liu J, Li Y, Yin X, Xu B, Jin Z. De novo characterization of the banana root transcriptome and analysis of gene expression under fusarium oxysporum f. Sp. Cubense tropical race 4 infection. BMC Genomics. 2012;13:650.

37. Bai TT, Xie WB, Zhou PP, Wu ZL, Xiao WC, Zhou L, Sun J, Ruan XL, Li HP. Transcriptome and expression profile analysis of highly resistant and susceptible banana roots challenged with fusarium oxysporum f. Sp. cubense tropical race 4. PLoS One. 2013;8(9):e73945.

38. Li X, Bai T, Li Y, Ruan X, Li H. Proteomic analysis of fusarium oxysporum $\mathrm{f}$. Sp. cubense tropical race 4-inoculated response to fusarium wilts in the banana root cells. Proteome Sci. 2013;11(1):41.

39. Wang Y, Xia Q, Wang G, Zhang H, Zhang JSX. Differential gene expression in banana roots in response to fusarium wilt. Can J Plant Pathol. 2017:39(2): $163-75$

40. Shen Z, Penton CR, Lv N, Xue C, Yuan X, Ruan Y, Li R, Shen Q. Banana fusarium wilt disease incidence is influenced by shifts of soil microbial communities under different monoculture spans. Microb Ecol. 2017:75(3): $739-50$. 
41. Shimono M, Sugano S, Nakayama A, Jiang CJ, Ono K, Toki S, Takatsuji H. Rice WRKY45 plays a crucial role in benzothiadiazole-inducible blast resistance. Plant Cell. 2007;19(6):2064-76.

42. Landi L, De Miccolis Angelini RM, Pollastro S, Feliziani E, Faretra F, Romanazzi G. Global transcriptome analysis and identification of differentially expressed genes in strawberry after Preharvest application of Benzothiadiazole and chitosan. Front Plant Sci. 2017:8:235.

43. Trapnell C, Roberts A, Goff L, Pertea G, Kim D, Kelley DR, Pimentel H, Salzberg SL, Rinn JL, Pachter L. Differential gene and transcript expression analysis of RNA-seq experiments with TopHat and cufflinks. Nat Protoc. 2012;7(3):562-78.

44. Wagner GP, Kin K, Lynch VJ. Measurement of mRNA abundance using RNAseq data: RPKM measure is inconsistent among samples. Theory Biosci. 2012;131(4):281-5.

45. Li S, Yu X, Lei N, Cheng Z, Zhao P, He Y, Wang W, Peng M. Genome-wide identification and functional prediction of cold and/or drought-responsive IncRNAs in cassava. Sci Rep. 2017;7:45981.

46. Young MD, Wakefield MJ, Smyth GK, Oshlack A. Gene ontology analysis for RNA-seq: accounting for selection bias. Genome Biol. 2010;11(2):R14.

47. Kanehisa M, Araki M, Goto S, Hattori M, Hirakawa M, Itoh M, Katayama T, Kawashima S, Okuda S, Tokimatsu T, et al. KEGG for linking genomes to life and the environment. Nucleic Acids Res. 2008;36(Database issue):D480-4.

48. Romeis T. Protein kinases in the plant defence response. Curr Opin Plant Biol. 2001;4(5):407-14.

49. Tang D, Wang G, Zhou JM. Receptor kinases in plant-pathogen interactions: more than pattern recognition. Plant Cell. 2017;29(4):618-37.

50. Jin J, Tian F, Yang DC, Meng YQ, Kong L, Luo J, Gao G. PlantTFDB 4.0: toward a central hub for transcription factors and regulatory interactions in plants. Nucleic Acids Res. 2017;45(D1):D1040-5.

51. Ishihama N, Yoshioka H. Post-translational regulation of WRKY transcription factors in plant immunity. Curr Opin Plant Biol. 2012;15(4):431-7.

52. Huang PY, Catinot J, Zimmerli L. Ethylene response factors in Arabidopsis immunity. J Exp Bot. 2016;67(5):1231-41.

53. Tsuda K, Somssich IE. Transcriptional networks in plant immunity. New Phytol. 2015;206(3):932-47.

54. Zhang Y, Feng JC. Identification and characterization of the grape WRKY family. Biomed Res Int. 2014;2014:787680.

55. Dang F, Wang Y, She J, Lei Y, Liu Z, Eulgem T, Lai Y, Lin J, Yu L, Lei D, et al. Overexpression of CaWRKY27, a subgroup Ile WRKY transcription factor of Capsicum annuum, positively regulates tobacco resistance to Ralstonia solanacearum infection. Physiol Plant. 2014;150(3):397-411.

56. Zhang G, Chen M, Li L, Xu Z, Chen X, Guo J, Ma Y. Overexpression of the soybean GmERF3 gene, an AP2/ERF type transcription factor for increased tolerances to salt, drought, and diseases in transgenic tobacco. J Exp Bot. 2009;60(13):3781-96.

57. Ali MA, Abbas A, Kreil DP, Bohlmann H. Overexpression of the transcription factor RAP2.6 leads to enhanced callose deposition in syncytia and enhanced resistance against the beet cyst nematode Heterodera schachtii in Arabidopsis roots. BMC Plant Biol. 2013;13:47.

58. Hamdoun S, Zhang C, Gill M, Kumar N, Churchman M, Larkin JC, Kwon A, Lu $H$. Differential roles of two homologous cyclin-dependent kinase inhibitor genes in regulating cell cycle and innate immunity in Arabidopsis. Plant Physiol. 2016;170(1):515-27.

59. Gao S, Gao Y, Xiong C, Yu G, Chang J, Yang Q, Yang C, Ye Z. The tomato Btype cyclin gene, SICycB2, plays key roles in reproductive organ development, trichome initiation, terpenoids biosynthesis and Prodenia litura defense. Plant Sci. 2017;262:103-14.

60. Shah J, Zeier J. Long-distance communication and signal amplification in systemic acquired resistance. Front Plant Sci. 2013;4:30.

61. Wang X, He X, Lin J, Shao H, Chang Z, Dixon RA. Crystal structure of isoflavone reductase from alfalfa (Medicago sativa L.). J Mol Biol. 2006;358(5): 1341-52.

62. Delaunois B, Jeandet P, Clement C, Baillieul F, Dorey S, Cordelier S. Uncovering plant-pathogen crosstalk through apoplastic proteomic studies. Front Plant Sci. 2014;5:249.

63. Houston K, Tucker MR, Chowdhury J, Shirley N, Little A. The plant cell wall: a complex and dynamic structure as revealed by the responses of genes under stress conditions. Front Plant Sci. 2016;7:984

64. Kemmerling B, Halter T, Mazzotta S, Mosher S, Nurnberger T. A genomewide survey for Arabidopsis leucine-rich repeat receptor kinases implicated in plant immunity. Front Plant Sci. 2011;2:88.
65. Sekhwal MK, Li P, Lam I, Wang X, Cloutier S, You FM. Disease resistance gene analogs (RGAs) in plants. Int J Mol Sci. 2015;16(8):19248-90.

66. Li X, Zhang Y, Yin L, Lu J. Overexpression of pathogen-induced grapevine TIR-NB-LRR gene VaRGA1 enhances disease resistance and drought and salt tolerance in Nicotiana benthamiana. Protoplasma. 2017;254(2):957-69.

67. Tang Y, Liu Q, Liu Y, Zhang L, Ding W. Overexpression of NtPR-Q up-regulates multiple defense-related genes in Nicotiana tabacum and enhances plant resistance to Ralstonia solanacearum. Front Plant Sci. 2017;8:1963.

68. Zhang L, Zhang F, Melotto M, Yao J, He SY. Jasmonate signaling and manipulation by pathogens and insects. J Exp Bot. 2017;68(6):1371-85.

69. Verma V, Ravindran P, Kumar PP. Plant hormone-mediated regulation of stress responses. BMC Plant Biol. 2016;16:86.

70. Banday ZZ, Nandi AK. Interconnection between flowering time control and activation of systemic acquired resistance. Front Plant Sci. 2015;6:174.

71. Ryals JA, Neuenschwander UH, Willits MG, Molina A, Steiner HY, Hunt MD. Systemic acquired resistance. Plant Cell. 1996;8(10):1809-19.

72. Smith HB. Signal transduction in systemic acquired resistance. Plant Cell. 2000;12(2):179-81.

73. Fierens E, Rombouts S, Gebruers K, Goesaert H, Brijs K, Beaugrand J, Volckaert G, Van Campenhout S, Proost P, Courtin CM, et al. TLXI, a novel type of xylanase inhibitor from wheat (Triticum aestivum) belonging to the thaumatin family. Biochem J. 2007:403(3):583-91.

74. Mackintosh CA, Lewis J, Radmer LE, Shin S, Heinen SJ, Smith LA, Wyckoff MN, Dill-Macky R, Evans CK, Kravchenko S, et al. Overexpression of defense response genes in transgenic wheat enhances resistance to fusarium head blight. Plant Cell Rep. 2007;26(4):479-88.

75. McLaughlin JE, Bin-Umer MA, Widiez T, Finn D, McCormick S, Tumer NE. A lipid transfer protein increases the glutathione content and enhances Arabidopsis resistance to a Trichothecene mycotoxin. PLoS One. 2015;10(6):e0130204.

76. Floerl S, Majcherczyk A, Possienke M, Feussner K, Tappe H, Gatz C, Feussner I, Kues $U$, Polle A. Verticillium longisporum infection affects the leaf apoplastic proteome, metabolome, and cell wall properties in Arabidopsis thaliana. PLoS One. 2012;7(2):e31435

77. Goulet C, Goulet C, Goulet MC, Michaud D. 2-DE proteome maps for the leaf apoplast of Nicotiana benthamiana. Proteomics. 2010;10(13):2536-44.

78. N VDB, Berger DK, Hein I, Birch PR, Wingfield MJ, Viljoen A. Tolerance in banana to fusarium wilt is associated with early up-regulation of cell wallstrengthening genes in the roots. Mol Plant Pathol. 2007;8(3):333-41.

79. Dalio RJD, Magalhaes DM, Rodrigues CM, Arena GD, Oliveira TS, Souza-Neto RR, Picchi SC, Martins PMM, Santos PJC, Maximo HJ, et al. PAMPs, PRRs, effectors and R-genes associated with citrus-pathogen interactions. Ann Bot. 2017;119(5):749-74.

80. Zuo W, Chao Q, Zhang N, Ye J, Tan G, Li B, Xing Y, Zhang B, Liu H, Fengler $K A$, et al. A maize wall-associated kinase confers quantitative resistance to head smut. Nat Genet. 2015;47(2):151-7.

81. Ranf S, Gisch N, Schaffer M, Illig T, Westphal L, Knirel YA, Sanchez-Carballo PM, Zahringer U, Huckelhoven R, Lee J, et al. A lectin S-domain receptor kinase mediates lipopolysaccharide sensing in Arabidopsis thaliana. Nat Immunol. 2015;16(4):426-33.

\section{Ready to submit your research? Choose BMC and benefit from:}

- fast, convenient online submission

- thorough peer review by experienced researchers in your field

- rapid publication on acceptance

- support for research data, including large and complex data types

- gold Open Access which fosters wider collaboration and increased citations

- maximum visibility for your research: over $100 \mathrm{M}$ website views per year

At BMC, research is always in progress.

Learn more biomedcentral.com/submissions 